Review

\title{
Object-Based Image Analysis in Wetland Research: A Review
}

\section{Iryna Dronova}

Department of Landscape Architecture \& Environmental Planning, 202 Wurster Hall \#2000, University of California Berkeley, CA 94720, USA; E-Mail: idronova@berkeley.edu

Academic Editors: Norman Kerle and Prasad S. Thenkabail

Received: 12 March 2015 / Accepted: 14 May 2015 / Published: 21 May 2015

\begin{abstract}
The applications of object-based image analysis (OBIA) in remote sensing studies of wetlands have been growing over recent decades, addressing tasks from detection and delineation of wetland bodies to comprehensive analyses of within-wetland cover types and their change. Compared to pixel-based approaches, OBIA offers several important benefits to wetland analyses related to smoothing of the local noise, incorporating meaningful non-spectral features for class separation and accounting for landscape hierarchy of wetland ecosystem organization and structure. However, there has been little discussion on whether unique challenges of wetland environments can be uniformly addressed by OBIA across different types of data, spatial scales and research objectives, and to what extent technical and conceptual aspects of this framework may themselves present challenges in a complex wetland setting. This review presents a synthesis of 73 studies that applied OBIA to different types of remote sensing data, spatial scale and research objectives. It summarizes the progress and scope of OBIA uses in wetlands, key benefits of this approach, factors related to accuracy and uncertainty in its applications and the main research needs and directions to expand the OBIA capacity in the future wetland studies. Growing demands for higher-accuracy wetland characterization at both regional and local scales together with advances in very high resolution remote sensing and novel tasks in wetland restoration monitoring will likely continue active exploration of the OBIA potential in these diverse and complex environments.
\end{abstract}

Keywords: object-based image analysis (OBIA); GEOBIA; wetland; review; sensors; monitoring 


\section{Introduction}

Global losses of wetland areas, increasing anthropogenic pressures on their resources and the uncertainty of future climate change effects urgently call for more sustainable and adaptive conservation and management strategies which, in turn, require better understanding of wetland ecosystem properties and spatio-temporal variation [1-3]. Yet, research abilities to detect and characterize wetland ecosystems and to monitor their dynamics are often constrained by the limited on-site access, the risk of disturbing vulnerable habitats and species, and high surface complexity caused by fine-scale variation in topography, hydrologic properties and vegetation [4-6]. These challenges make it difficult to obtain sufficiently large, representative and repeated samples from the field surveys in wetlands and thus to generalize ecological information across broader landscapes $[7,8]$.

These limitations have increasingly encouraged applications of remote sensing data from satellite, airborne and more recently unmanned aerial vehicles (UAVs) for wetland analyses and monitoring. Remote sensing offers the benefits of capturing extensive study areas at the same state of plant phenology or inundation, spectral sensitivity of sensors to variation in wetland surface composition, and greater cost efficiency of repeated data collection compared to field surveys [9-11]. However, the overall success and practical utility of remote sensing-based wetland assessments have been contingent on the accuracy of image interpretation and feature extraction. Achieving high accuracy in wetland environments may be challenging [10], particularly with image pixels as primary mapping units. First, heterogeneity in local pixel values, variable soil moisture and spectral similarities among cover types often constrain discrimination of classes and lead to infamous "salt-and-pepper" speckle in the mapping outputs [12-14]. Second, spatial resolution of commonly used image datasets (such as 30-m Landsat) is frequently insufficient to detect fine-scale wetland features and class boundaries, and spectral mixing of different classes at subpixel scales may reduce mapping accuracy [15-17]. Finally, pixel-based approaches may be limited by the lack of ecologically meaningful information on spatial context and class neighborhood relationships in the pixel grid structure [18], unless ancillary geospatial or field information is available to inform wetland delineation and classification.

Object-based image analysis (OBIA) offers a promising framework to address these constraints in heterogeneous wetland landscapes and to facilitate repeated monitoring of their composition and surface properties. In OBIA, the images are first segmented into "objects" that are groups of pixels representing ground patches, entities or their elements (primitives) which subsequently can be classified into categories of interest by unsupervised, supervised or rule-based algorithms [14,19,20]. The key benefits of OBIA relative to pixel-based methods include: (1) the possibility to incorporate object-level shape, texture and relevant contextual variables into classification, in addition to spectral values of the input image layers [19,20]; (2) smoothing some of the local variation within objects, which may reduce the salt-and-pepper noise and enhance classification accuracy [13,17,21,22]; and (3) accounting for the landscape hierarchy of patch, cover type and ecosystem structure by working with multiple object layers nested within each other at different spatial scales [23-26]. The approximation of ground entities and patches by image objects makes them more ecologically relevant and potentially more resilient to minor geospatial positioning and image registration error than pixel units $[5,27]$.

Over the recent decades, object-based methods have been used in a broad array of wetland studies, from detection and delineation of wetland bodies in different landscapes to comprehensive analyses of 
within-wetland cover types and their change [28]. Several studies reported the improvement in wetland classification accuracy with OBIA compared to pixel-based methods up to $31 \%$ [22,24,29,30]. However, it remains unclear whether the challenges of wetland environments can be uniformly addressed by OBIA across different types of data, spatial scales and research objectives, and to what extent technical and conceptual aspects of this framework may themselves present challenges in a complex wetland setting [28]. Among previously published literature reviews, those focusing on OBIA progress have predominantly included studies from non-wetland landscapes [20,31], while the reviews of remote sensing applications in wetlands [9-11] have not aimed at detailed discussions of OBIA-specific issues. Thus, the time for a targeted synthesis of the OBIA progress and challenges in wetlands is ripe given the demand for novel OBIA applications in wetland restoration projects and exotic species monitoring $[3,8,32]$ and the growing use of high- and very-high resolution imagery from new remote sensing platforms such as UAVs [33-35]. New insights about technical and conceptual limitations of OBIA in wetlands [28] also highlight the urgent need to better understand the nature of present constraints and develop solutions in the future research efforts.

This paper presents a synthesis of 73 studies that used OBIA in different types of wetlands, either published or available online before 31 December, 2014. The main objectives of this assessment were: (1) to review the progress and scope of the OBIA applications in wetland environments; (2) to summarize the key strengths and unresolved challenges of this framework in the context of wetland remote sensing research; and (3) to discuss the main needs and future directions to expand the potential of OBIA in wetland analyses. The synthesis is organized as follows: Section 2 provides the overview of research objectives, data and geographic context of the included papers; Section 3 introduces basic OBIA principles and discusses key benefits of OBIA for wetlands, while Section 4 addresses the main factors affecting OBIA accuracy and current limitations. Section 5 concludes with the summary points and a review of the future research needs.

\section{The Scope of Reviewed Papers}

\subsection{Research Objectives and Focus}

This review focused on 73 papers selected from the literature searches in ISI Web of Science and ProQuest databases and several references cited in earlier manuscripts and reviews, either published or available online before 31 December 2014 (more than half were published in or after 2009). These included peer-reviewed journal articles, conference papers and chapters of book and $\mathrm{PhD}$ thesis publications. This review specifically focused on vegetated wetlands (i.e., colonized by aquatic macrophytes) of diverse types [36] such as fresh- and salt-water estuarine, riverine, lacustrine, palustrine and selected marine (mangrove) ecosystems (Table 1, [5-8,12,13,15-18,22-30,32,34,37-87]) and excluded studies of solely deepwater and open-water aquatic ecosystems such as seagrass beds. The OBIA applications and main research objectives fell into several broad groups (with some papers applicable to more than one of these):

(1). Wetland detection \& delineation: studies detecting wetland presence and/or delineating their boundaries in landscapes with significant proportion of non-wetland natural and anthropogenic land cover [14-16,18,26,29,38-40,55,63,64,73,74,84-87]. 
(2). Typological classification of delineated wetland units: assignment of mapped wetland bodies into hydrological, geomorphological and ecological categories without detailed mapping of within-wetland cover $[6,27,29,37,43,44,55,65,66,73,79,80]$;

(3).Classification of within-wetland cover types and/or vegetation: mapping within-wetland surface composition and vegetation types, sometimes targeting specific classes such as invasive plant species (e.g., [5,8,12,13,17,23-25,28,30,32,34,41,45,48-50,52,53,57,68,69,74-77,79-85]);

(4).Analysis of wetland change over a particular period of time $[7,34,39,46,48,55,59,67,86]$;

(5).Analysis of within-wetland biophysical and ecological properties using OBIA outcomes for subsequent ecological study: wildlife habitat analyses [25,26,56,58,63], spatial modeling of ecosystem properties such as carbon stocks [70], net primary productivity [78], wetland geomorphology and vegetation structure $[42,77,88]$, and analyses of disturbance $[60,61,64]$.

Table 1. General characteristics of reviewed studies by major geographic region.

\begin{tabular}{|c|c|c|c|c|}
\hline Region & No. & Wetland Types and Corresponding References & $\begin{array}{l}\text { Study Area } \\
\text { Range }\left(\mathbf{k m}^{2}\right)\end{array}$ & $\begin{array}{l}\text { Spatial } \\
\text { Resolution (m) }\end{array}$ \\
\hline Africa & 4 & $\begin{array}{l}\text { River floodplain [37] and inland seasonally flooded freshwater [38]; } \\
\text { mangroves and coastal marshes }[39,40]\end{array}$ & $134.6-6400$ & $12.5-30$ \\
\hline Australia & 4 & Mangroves [22] and riparian wetlands $[59,79]$ & $2-10$ & $2.4-4$ \\
\hline Canada & 12 & $\begin{array}{l}\text { Diverse peatland types [27,43-47], coastal freshwater and estuarine } \\
\text { marshes [48-50], river floodplain [51], small isolated freshwater } \\
\text { wetlands [26] and riparian [52] }\end{array}$ & $16-1467$ & $0.2-30$ \\
\hline China & 10 & $\begin{array}{l}\text { Inland seasonally flooded freshwater }[7,17,53,54] \text {, } \\
\text { river floodplain wetlands }[55,56] \text {, coastal salt marshes }[34,57,58] \text {, } \\
\text { alpine wetlands of Tibet Plateau }[55,59]\end{array}$ & $2.3-356,000$ & $0.61-32$ \\
\hline $\begin{array}{l}\text { Other South \& } \\
\text { East Asia }\end{array}$ & 6 & $\begin{array}{l}\text { Tropical peat swamps }[60,61] \text {, peatland [5], mangroves }[24,62] \\
\text { and river floodplain }[63]\end{array}$ & $0.1-5331$ & $0.02-30$ \\
\hline Europe & 9 & $\begin{array}{l}\text { Diverse peatland types and bogs [64-67], river floodplain [68-71] } \\
\text { and coastal saltwater marshes [72] }\end{array}$ & $0.4-1500$ & $0.3-30$ \\
\hline Siberia & 1 & Peatland [73] & 125,000 & 300 \\
\hline $\begin{array}{l}\text { Central \& } \\
\text { South America }\end{array}$ & 11 & $\begin{array}{l}\text { River floodplains }[74-78] \text {, inland permanent and seasonally flooded } \\
\text { freshwater wetlands }[79,80] \text {, mangroves }[12,23,81,82]\end{array}$ & $16-1,777,000$ & $1-125$ \\
\hline USA & 16 & $\begin{array}{l}\text { River floodplain wetlands }[8,29,83] \text {, coastal freshwater, brackish } \\
\text { and salt marshes }[13,25,28,30,32,84,85] \text {, isolated freshwater } \\
\text { wetlands of different types }[6,15,16,18,86,87]\end{array}$ & $0.4-5,400$ & $0.2-30$ \\
\hline
\end{tabular}

The studies represented various wetland regions of the world, but most of them were conducted in North America (USA and Canada), Central and South America and China (Table 1). Although their spatial extent varied greatly, most analyses focused primarily on wetland mapping or change detection for one or more of the common research objectives listed above. Wetland types represented in this review were also diverse, including coastal freshwater and tidal marshes, mangroves, freshwater wetlands in river floodplains, riparian ecosystems, diverse wetland types in peatland landscapes, tropical peat swamps and small isolated freshwater wetlands with scattered distribution (Table 1). Several analyses were conducted in spatially extensive and biologically diverse wetland regions of international importance and sites of protected status under Ramsar Convention, such as Poyang Lake [7,17,53,54], 
Dongtan Nature Reserve [58] and Xianghai and Zhalong wetlands [56] in China, Brazilian Pantanal wetlands in South America [79,80], Kushiro wetland in Japan [5], Koshi Tappu Wildlife Preserve in Nepal [63], and European Eider Treene Sorge Lowland [65], Danube Floodplain [68] and Biebrza River Valley [71], as well as other protected areas including Florida Everglades National Park in USA [8,83] and other nature reserves and wildlife refuge sites [28,34,67].

\subsection{General Characteristics of Input Data and Classification Accuracy}

The reviewed studies varied in spatial resolution, spatial extent and spectral characteristics of the input data (Table 1, Figure 1). There was a strong positive correlation between log-transformed size of study area and spatial resolution (or pixel size in ground units) of the primary remote sensing data $\left(\mathrm{R}^{2}=0.61, p\right.$-value $<0.001$; Figure 1$)$, suggesting that on average, studies focusing on smaller spatial extents tended to use higher-resolution imagery. At the same time, there was a substantial variation in landscape size in applications of popular medium-resolution sensors such as Landsat (30 m).

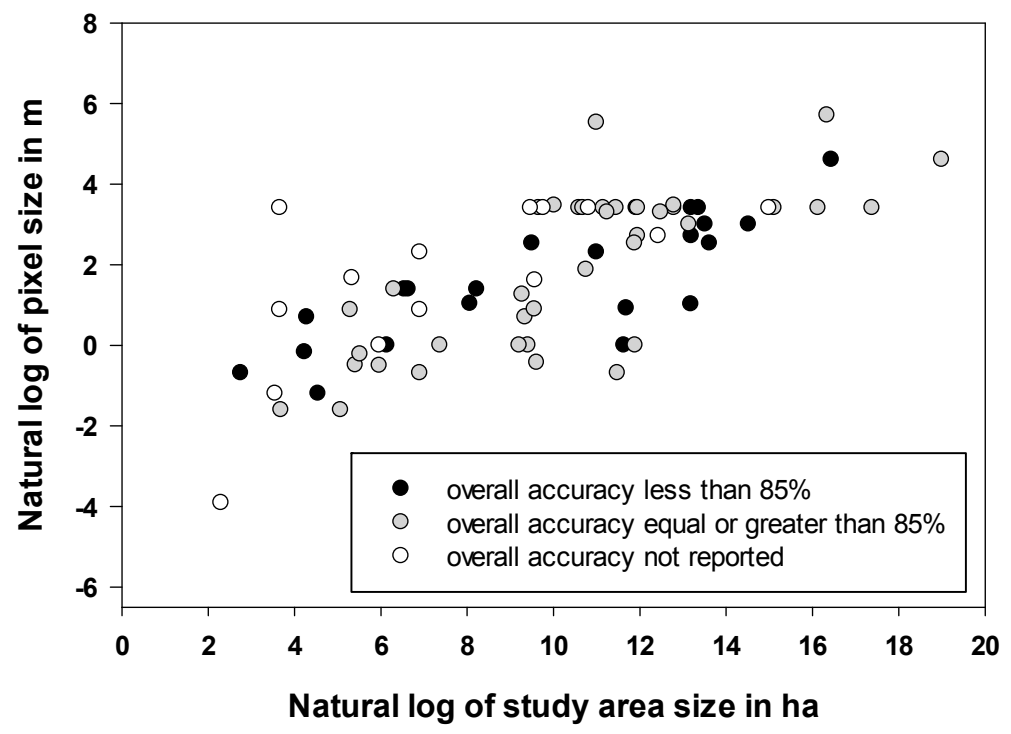

Figure 1. Spatial scale of the reviewed papers: significant positive correlation between $\log$-transformed study area size and spatial resolution $\left(\mathrm{R}^{2}=0.61, p\right.$-value $\left.<0.001\right)$.

The majority of studies used broadband "passive" remote sensing data acquired in visible, near- and mid-infrared electromagnetic spectral regions. Among these, spatial resolution varied from 125 to $300 \mathrm{~m}$ of Moderate Resolution Imaging Spectroradiometer (MODIS) and Medium Resolution Imaging Spectrometer (MERIS) to moderate-resolution (10 to $32 \mathrm{~m}$ ) data from missions such as Landsat, SPOT, Beijing-1 $[7,15,17,23,38,56,59,65,86,88]$ and high-resolution (pixel size $\leq 4 \mathrm{~m}$ ) commercial satellite and aerial imagery with pixel size up to $0.15 \mathrm{~m}$ from a UAV [34] and $0.02 \mathrm{~m}$ from a balloon and camera system [5]. Four studies used hyperspectral airborne imagery at high resolutions between 0.6 and $4 \mathrm{~m}$ for classifying wetland communities and species in Florida, USA $[8,83]$, mapping mangrove species in Australia [22] and river floodplain cover types in a small area in Iowa, USA [29].

Seventeen studies used the data from synthetic aperture radar (SAR) either as the primary input or in combination with Landsat or other sensors [27,37,40,43,47,53,54,71,73-80,82]. Most of these utilized the data from Radarsat, Radarsat-2 and JERS-1 missions [47,73-77,79]; some used ENVISAT ASAR [37,53,54] 
and ALOS PALSAR [40,79,80]; spatial resolution of these datasets varied between 10 and $100 \mathrm{~m}$. Radar images as inputs to OBIA have been especially critical for wetland analyses in humid regions with frequent cloud cover limiting the availability of multi-spectral images and the consistency of seasonal time series $[37,75,82]$. Several high-resolution studies using multi-spectral imagery additionally incorporated light detection and ranging (lidar) datasets to facilitate the overall wetland classification or discrimination of specific classes and landscape features $[6,25,28,32,59,71,77,80,89]$. The importance of data type and spatial resolution for wetland analysis outcomes will be discussed among the factors affecting OBIA accuracy in Sections 4.2 and 4.3.

\section{Strengths and Benefits of the OBIA Framework in Wetland Analyses}

\subsection{Background on General OBIA Principles}

The purpose of this section is to introduce the basics of OBIA terminology and implementation. The OBIA process typically starts with segmentation of input images into local groups of pixels, i.e., objects that become spatial units in subsequent analysis, classification and accuracy assessment [19]. Object shape, size and spectral properties depend on research goals and segmentation approach. Various techniques exist such as "top-down" algorithms splitting the image into smaller regions based on spectral value thresholds or constraints on local variation, bottom-up region-growing methods that derive objects by merging pixels locally, and more complex approaches combining top-down and bottom-up logic [20,90]. The goal of segmentation is often to approximate meaningful landscape entities recognizable at a given image resolution (e.g., buildings, vehicles or trees in aerial photos [91-93]). However, in complex landscapes with variable patch characteristics, "typical" objects may be hard to define, and segmentation is used to produce smaller, spectrally homogeneous "primitive" objects that can be classified into larger cover type extents. This is frequently the case in wetlands, and most of the reviewed studies used primitive objects as spatial units of analysis.

Segmentation outputs are often controlled by parameters that constrain within-object spectral variation, or heterogeneity, as well as other method-specific criteria. For instance, with popular multi-resolution segmentation approach (MRS; [94]), the outcome of different-sized objects is determined by the choice of input image bands and their relative weights, relative importance of shape (geometry) versus color (spectral) properties and by scale which controls allowable within-object heterogeneity. As a result, large number of potential object layouts becomes possible, and choosing among them is difficult even when relying on expert knowledge. Recently, new tools have been proposed to facilitate automatic decision on segmentation specifications, such as the Estimation of Scale Parameter (ESP) tool for MRS (ESP; $[95,96]$ ), but they have not been extensively tested in wetlands yet.

Object classification may be performed by supervised, unsupervised and rule-based methods similar to pixel-based analyses; however, with objects as spatial units there is a wider choice of candidate features to facilitate discrimination. In addition to spectral variables, objects and their class-related typologies may be characterized by geometry (e.g., area, perimeter, various shape indices), texture (metrics of within-object variation in pixel values of a given band) and "contextual" metrics describing adjacency or distance to classes, spectral differences with neighbors or relationships with objects from other levels of segmentation hierarchy. Classification may be conducted either instantaneously by a 
single classifier algorithm, or as a multi-step process combining simple threshold rules and statistical classifiers at different object levels and data subsets according to research goals. Hierarchical classifications are also common, where class identities at one object level are used to inform discrimination at the next level in top-down or bottom-up direction [22,23,68].

Accuracy in OBIA outcomes may be assessed at either segmentation or classification steps, depending on research objectives. Segmentation accuracy focuses on the geometric match between landscape entities and image or class objects by measuring the degree of over- and under-segmentation of the target reference units [93]. For classification, accuracy is typically assessed as a match between the identity of reference ground locations and their assigned image classes using a traditional confusion matrix or fuzzy accuracy metrics in mixed-cover areas. The use of "point" matches between object-based classification outputs and reference data requires caution, because test locations may not be independent if they fall inside the same object. In studies focusing on delineation of a single class (such as "wetland" or "water"), alternative accuracy metrics may be used describing frequencies, spatial extent or size ranks of detected targets relative to all reference units [18,86,87].

Finally, the process of OBIA implementation greatly varies among studies and depends on both research objectives and the software. Among the reviewed publications, the most common software choice was eCognition (Trimble Inc.; formerly by Definiens Inc. with some of earlier versions also named Definiens) which allows developing custom algorithm sequences, or "rule sets" combining segmentation, classification and other steps of data analysis, refinement and export. This software also facilitates hierarchical segmentations into multiple object layouts ("levels") for the same image, where the boundaries of larger upper-level objects are preserved within the lower-level geometry. Examples of other software included VLS Feature Analyst (FA) in [64]; BerkeleyImgSeg [87], ENVI (ZOOM) feature extraction module (Exelis VIS Inc.) [59], rule-based and thresholding procedures in ESRI ArcMap [86] and open-source SPRING [74] developed in the National Institute for Space Research of Brazil (INPE) which more recently has contributed to the next open-source OBIA software InterImage by the Computer Vision Laboratory of the Department of Electrical Engineering of the Catholic University of Rio de Janeiro. One study [44] performed segmentation with the Sized-Constrained Region Merging (SCRM) software written in the Interactive Data Language (ITT Visual Information Solutions Inc.) and classification - with the data mining tool See5 for C 5.0. Several other OBIA tools exist such as IMAGINE Objective add-on for ERDAS IMAGINE (Hexagon Geospatial Inc.) and open-source Monteverdi 2 by Orfeo Toolbox, but these were not used in reviewed wetland studies.

\subsection{Using Image Segmentation to Address Heterogeneity and Noise}

In the reviewed analyses, OBIA offered several critical advantages to pixel-based approaches, such as the possibility to work with ecologically relevant spatial units at different scales and incorporation of non-spectral information in object generation and classification. These approaches also frequently resulted in smoothing of the local noise at object level and reduction of the "salt-and-pepper" speckle in classification outputs. Speckle is a common problem in wetland studies that may originate both within monotypic cover types due to intrinsic spectral variation and within mixed areas due to fine-scale patchiness and diversity of plant composition [7,25,57]. This problem becomes especially notorious with high-resolution data where greater spatial detail and color variation may expose non-relevant landscape 
elements (shadows, branches) and limit the accuracy for target entities [13,26]. Averaging pixel values at the object level smoothens local variation and often reduces the influence of marginal, mixed and unusually colored pixels $[26,37,57,74]$. As a result, classification accuracy may increase with greater average object size or heterogeneity relative to pixel units, as reported in wetland studies using very high-resolution aerial photography [13], medium-resolution Landsat data [17] and in non-wetland analyses [97]. Similarly, aggregation of pixels to coarser resolutions prior to segmentation may increase the accuracy initially but ultimately reduce it with overly large input units [44].

Smoothing of the local noise at object level was particularly useful in studies using SAR data to map wetland cover types in Amazon floodplain [74-76], Brazilian Pantanal [79,80] and northern forested regions of Canada [27] and Siberia [73]. Radar backscatter may exhibit substantial speckle due to complexity of both horizontal and vertical structure of wetland ecosystems which affects relative contributions of different scattering modes and thus the local variation of the modified signal $[37,73]$. Averaging of the radar pixel values at the object level often facilitated delineation of wetland units and vegetation types and enhanced their correspondence to semantic objects of interest across the gradients of inundation [27,37,54,74,75,80]. Similar noise-alleviating benefits were also important in studies combining radar and multi-spectral Landsat or MODIS data via hierarchical OBIA to enhance the accuracy of mapping floodplain vegetation types, e.g., in the Amazon River and tributaries [77,78].

Importantly, the advantage of image object units for "smart filtering" of the local noise often facilitated wetland classifications despite the lack of "typical" or "standard" semantic objects for a given class in these complex environments [49]. In most reviewed studies, the outputs of initial segmentation represented patch elements, or "primitive" objects, while larger patches and semantic entities (e.g., vegetation classes or habitat types) were recovered later via classification of these primitives $[17,25,58]$. Smoothing of the local variation at the primitive object level may enhance the contrast among landscape elements and facilitate not only classifications, but also spatial modeling with geographic information science (GIS) tools using objects as units of analysis. For instance, two studies in different wetland regions of China [56,58] used primitive objects generated by multi-resolution segmentation as spatial units for GIS-based bird habitat suitability analysis and modeling. An inevitable challenge, however, is choosing the most "optimal" segmentation layout from large array of possible parameter combinations, as discussed in more detail in Section 4.4 below.

\subsection{Detection and Delineation of Wetlands as Landscape Units}

A number of studies applied OBIA to delineate wetlands as semantic objects, either as a standalone task or to isolate wetlands for subsequent analysis. Such delineation can be greatly facilitated by unique spectral, textural and geomorphological characteristics of wetlands that contrast with adjacent upland areas and open water $[15,16,18,87]$. These properties may include distinctive soil moisture content and inundation affecting reflectance in moisture-sensitive bands [16,26] and backscatter in radar sensors $[73,74]$, or unique geomorphological structure and landscape position shaped by topographic and hydrological factors $[41,77,84-86]$. These characteristics may assist in separating wetlands from other land cover types due to greater contribution of the surface and soil moisture to spectral signals, reflectance of water through canopy gaps and presence of specialized hydrophilous vegetation with unique spectral properties compared to upland plants $[30,48,59]$. 
At the image object level, a number of physically meaningful non-spectral attributes may also accentuate wetland presence and extent. For instance, shape, size, spatial relationships and adjacency metrics helped to finalize detection of isolated wetlands by separating them from wetlands connected to water bodies in [15]. Some studies utilized image texture, or metrics of spectral heterogeneity and landscape patterning, in wetland detection, as either object-level texture attributes or as ancillary input image layers to OBIA [16,39]. Smoothing of local spectral variation at the object level may further enhance spectral contrasts among "wetter" and "drier" landscape units and facilitate delineation of wetland bodies as discrete entities $[15,16,18]$.

The OBIA framework also makes it convenient to combine multiple complementary datasets for wetland delineation without overly complex data fusion $[73,77]$. In particular, digital elevation models may elucidate topographic properties and landscape position of wetlands and to predict potential zones of soil saturation based on topographic-hydrological feedbacks $[47,68,77,86]$. For instance, an effort to detect small (median area of $0.67 \mathrm{ha}$ ) palustrine emergent wetlands in semi-arid California Sierra-Nevada Foothills [87] combined multi-spectral IKONOS imagery with topographic information derived from DEM, thus highlighting the contrasts between small wetlands and irrigated pastures or other upland cover types. A study in the USA's Prairie pothole region [86] developed binary water/non-water maps and performed terrain analysis to identify depressions, which then facilitated unsupervised cluster-based classification of wetlands according to their hydrological function. In locations with complex and locally variable terrain, topographic properties highlighting locations of wetland and riparian features may be also derived from lidar data $[6,41,42,70]$. Delineation of wetland units as discrete objects is often an important first step of hierarchical approaches prior to identifying different classes of wetland systems [73] or mapping within-wetland cover types and habitats [26,41].

An important challenge in wetland delineation is potential "fuzziness" and positional uncertainty of their spatial boundaries, especially in areas with complex inundation gradients and mixed vegetation forming transitional fringes [7,15,55]. Standing tall vegetation may also obscure wetland boundaries [88] and reduce the extent of detectable area, which may be an important concern for mapping smaller wetland bodies [86]. The issue of fuzziness may be at least partially addressed by (1) assessing hydrological variability at different dates to obtain more "generalized" boundaries [86]; (2) when possible, incorporating high-resolution images or ancillary data to improve the precision of delineation [48]; and (3) focusing on detection of wetland presence and prevalent extent, rather than boundary precision per se [15]. Some studies also suggested using subpixel estimates of percent water cover to improve delineation accuracy, particularly in small wetlands [86]. Notably, from an ecological standpoint, fuzzy boundaries are both interesting and important as transition zones between marshes and adjacent uplands that have been of growing interest to management in face of the threats posed by the sea level rise in flood-prone landscapes [98]. OBIA may be used to delineate specific wetland zones based on hydroperiod, local topography and phenology $[7,45,53]$ and facilitate their repeated monitoring.

\subsection{Stepwise and Hierarchical Relationships in Advanced Wetland Classifications}

The possibility to perform OBIA at spatially linked "nested" object levels greatly facilitates hierarchical approaches to classification of wetland ecosystems. The utility of such hierarchies was recognized in earlier pixel-based studies $[99,100]$ demonstrating that to more reliably classify wetland 
components, wetland units first have to be differentiated from other landscape elements. Furthermore, spatial complexity of wetland cover types may limit the capacity to classify them in a single effort and instead may call for the use of different discriminating features and even spatial scales for different class groups [17,25]. For instance, in [28] broader salt marsh vegetation zones were more effectively detected with objects from $1 \mathrm{~m}$ CIR satellite imagery, while surface water channels were more easily distinguished from $0.3 \mathrm{~m}$ RGB aerial photography. In [17], specific wetland plant functional types differed in object scale which maximized mapping accuracy for individual classes from Landsat data. Hierarchical procedures my accommodate these different requirements at individual analysis steps while preserving object boundaries across the levels of the classification scheme $[23,25,27,62,68]$.

The key benefit of hierarchical OBIA in wetlands is in the possibility to account for spatially "nested" physical and ecological aspects of their organization. As landscape units, wetlands often exhibit unique spectral properties due to their moisture status, vegetation and spatial configuration $[18,39,86,87]$; therefore, it is reasonable to separate them from upland cover types prior to mapping their internal features. In turn, hydrological and topographic variation within wetlands may shape unique regimes and geomorphological features such as mudflats $[45,53,68,78]$ and "zones" of vegetation types with different flooding adaptations along the gradients of elevation and bathymetry [17,28,71,78,84,101,102]. Differences in morphology, color and phenology within such zones form important landscape context for individual elements of wetland cover $[28,32]$ and, thus, provide useful strata for characterizing more specific ecosystem properties and habitats $[25,58]$.

Specific strategies of hierarchical OBIA implementation in reviewed studies varied due to unique landscape structure of wetland regions, research objectives and input data. Some analyses started by separating wetlands from other cover types before delineating wetland-specific elements $[26,49,62]$, sometimes with the help of ancillary information from wetland inventories and similar sources $[26,27,50,64,71,89]$. In contrast, other studies performed bottom-up aggregation of primitive objects and small landscape elements (e.g., patches, trees, bushes) into more general surface classes or wetland types [67]. Several studies combined both top-down and bottom-up analyses to delineate complex semantically and spatially structured groups, for example, mangrove communities amidst other wetland classes in [22] and [23], or wetland vegetation types in the river floodplain [68] shaped by hydrological units and inundation regimes. Greater complexity of hierarchical procedures, however, would be likely to limit their transferability, calling for more coherent strategies of their development. Particularly promising are the new tools for automated selection of segmentation parameters that may simultaneously identify multiple meaningful and hierarchically connected scales of object delineation — such as the ESP tool for MRS in eCognition $[95,96]$.

\subsection{Diversity of Object-Level Variables for Class Delineation and Discrimination}

\subsubsection{Spectral Variables}

Remote sensing classifications of wetland cover are often challenged by spectral confusions resulting from strong effects of moisture on reflectance and backscattering, spectral variation in mixed areas [50] and presence of senescent vegetation obscuring unique signals of live communities [51]. As a result, spectral variables alone may not always separate classes sufficiently well [13]. Object-based analyses allow 
incorporating textural, geometric and contextual features defined at the level of object units, which together with spectral attributes produce a rich pool of candidate variables for both instantaneous $[6,50,53]$ and multi-step classifications $[23,32]$.

It is important to note that among reviewed studies spectral attributes based on the image bandwidths were still the most common discriminating features [6,27,28,81]. Most analyses incorporated object-level values of image bands sensitive to surface moisture and vegetation greenness (e.g., red, green, near-infrared) and their mathematical combinations such as normalized difference vegetation index (NDVI) $[6,7,39]$ and band ratios [32,45]. A much wider choice of spectral bands and indices is possible with hyperspectral remote sensing; however, such data have been relatively less common in object-based wetland studies. Four analyses in this review used airborne hyperspectral images to characterize general cover types [29] and wetland-specific vegetation groups and species [8,22,83]. Prior to OBIA, these studies determined the most useful bands with the aid of data-reducing statistical techniques such as minimum noise fraction transformation.

With radar data, spectral variables represent the backscattering signal after the radar pulse has interacted with wetland surface and thus provide critical information for discriminating surface cover types. Depending on the sensor wavelength, polarization, incident angle and structure of vegetation, the backscatter response may be dominated by surface scattering, volume scattering, or by "double-bounce" effect caused by the signal's interaction with multiple surfaces inside deeper canopies, e.g., tree trunks and water in flooded forests [37,74-76]. SAR wavelength plays an important role in object-based classifications; for instance, the shorter-wavelength C-band was useful for detecting herbaceous marsh vegetation $[37,78]$ but had limited sensitivity in forests [37,103]; while the longer L-band wavelength was sensitive to size of scattering elements in woody canopies and thus especially informative in forested wetlands [77,82]. In all the studies using SAR data, signal properties at the object level were typically more important than non-spectral attributes for differentiating ecosystems with diverse plant morphology and canopy structure, such as flooded forests, herbaceous marshes, man-made wetlands and rice paddies $[27,37,71,74,75,78,80,82,104]$. Finally, with lidar data, the return signals following interaction with wetland surfaces have to be preprocessed into raster models of terrain elevation, canopy surface metrics or other topographic and structural indices before they can be summarized in OBIA or integrated with other remote sensing data $[6,28,41,69,88]$. Most wetland studies utilized lidar information as complementary to primary multi-spectral variables, except two riparian studies relying primarily on lidar-based structural metrics in woody canopies $[69,88]$.

\subsubsection{Texture Variables}

Among the non-spectral attributes, texture variables were the most commonly discussed and perhaps the most controversial in terms of their added benefits to object-based classification. Texture may be evaluated by various metrics of heterogeneity in pixel values within a defined neighborhood, from simple standard deviation of spectral bands to more computationally demanding grey level co-occurrence matrix, or GLCM [105] functions [26,27,43,46,48,72,103]. In the reviewed studies, texture metrics were used both at the pixel level as inputs to initial segmentation [16,18,24,30,46], and as object-level attributes estimated from informative spectral bands such as near-infrared $[18,48]$. 
The key benefit of texture metrics is that, given the appropriate spatial scale, they may capture the unique "patterns" of spatial configuration and spectral variability among cover types and assist in their discrimination, sometimes compensating for limited spectral information in the input data $[13,30]$. "Characteristic" textural properties may be found in wetland vegetation types which exhibit unique spatial arrangement and density of dominant plant species $[17,48]$ or specific distribution of gaps in woody canopies. For instance, in the study of Thailand mangroves [24], distribution of canopy gap sizes promoted development of lacunarity metrics to facilitate classification of mangrove species. Interesting metrics of texture based on Japanese Earth Resources Satellite-1 (JERS-1) radar data were proposed for a broad-scale wetland mapping in Siberia [73], derived as local estimates of variance in the smooth signal and wavelet coefficients to highlight differences in landscape configuration among riparian, forested and bog wetland features. Metrics of "geotexture" based on variation in local neighbor objects were used in classification of boreal wetland types in Canada in [44].

The overall utility of texture for wetland classifications, however, was not universal. Several studies of marshes dominated by herbaceous vegetation reported the lack of improvement in accuracy with added texture at different input data resolutions [17,57,72]. The analysis of a salt marsh in the Yangtze River Estuary with $0.61 \mathrm{~m}$ pan-sharpened IKONOS imagery [57] attributed the lack of textural benefits to the likely similarity in texture among saltmarsh plant types. In the study of wetland plant functional types using Landsat data [17] characteristic fine-scale spatial patterns of disturbed reed patches had likely been "smoothed" at the level of 30-m pixels even before segmentation thus reducing the informative value of texture. In the classification of wetland vegetation in the Hudson River Estuary [30], texture was useful for improving the overall classification accuracy, but not as beneficial for the accuracy of the target invasive species class. Generally, the strongest benefits of texture were found in studies using high resolution $(\leq 4 \mathrm{~m})$ data and target classes with substantial differences in spatial patterning, such as vegetation, water and bare mud in [13].

\subsubsection{Shape and Contextual Variables}

Geometric attributes describing object shape and size were overall less frequently used in wetland analyses than spectral and texture metrics. In part this could be explained by common reliance on small, geometrically similar primitive objects as mapping units. However, even larger, "whole" patches of wetland cover types may exhibit large variation in geometric properties. For instance, bodies of open water may occur within the same landscape as linear features (streams and rivers), variable-sized and more "compact" units (small lakes and ponds), or large standalone objects (large reservoirs and portions of sea/ocean). Water channels may be difficult to accurately classify even with high-resolution data when they vary in sinuosity and when presence of floating aquatic macrophytes makes them similar to other cover types $[28,30,49]$. Not surprisingly, shape and size metrics were most beneficial when research objectives targeted wetland elements of a particular geometry type. For instance, in [26] such metrics were used to characterize partially submerged "linear" logs as wetland turtle habitat elements. Object area facilitated classification of small isolated wetlands within the matrix of rangeland and agriculture in [87] and delineation of wetland shrub cover types in [50]. Shape index (a measure of deviation from an idealized geometry such as square or circle) was used as one of the attributes for delineating the swamp class in a Quebec landscape [43]. 
Contextual variables describing adjacency, distance and neighborhood relationships were typically used after the results of segmentation or primitive object classification had been already integrated to "whole" patches of classes, making spatial associations among objects more meaningful. The most commonly used variables included proximity, adjacency, distance and relative border to "benchmark" classes affecting position of other surface types along the gradients of inundation, such as water bodies, channels, or streambeds $[25,27,41,81]$. To facilitate discrimination of riparian cover types in Australian tropical savannas [41], several contextual variables were utilized, including relative border to riparian vegetation and presence of and distance to streambed. In some cases, contextual relationships allowed to refine already developed classifications by re-assigning small misclassified objects within larger patches [6] and to address specific confusions among selected class pairs, such as between shrubs and floating vegetation in [50] and between two cattail species in [25]. Useful contextual information may also be provided by object attributes that had been "inherited" from higher or lower hierarchical levels $[39,72]$, such as the identities of more general landscape units.

In summary, most of the reviewed studies took advantage of the rich palette of class-discriminating features available at the level of objects, even when these objects were patch primitives rather than whole patches. The OBIA framework also facilitated the use of ancillary datasets and complementary sources to generate class-discriminating object attributes such as digital elevation models [56,59,84,86,87], lidar-based terrain and canopy surface models $[6,32,41,42]$ and existing spatial data on hydrological, soil and other wetland components $[16,26,29,43,50,65,68,73,80,89]$. However, a large variety of possible object features creates the challenge of choosing the best-discriminating ones while minimizing their redundancy $[28,53]$, which will be discussed in Section 4.5 below.

\subsection{Object-Based Approaches for Wetland Change Analysis}

Smoothing of the local noise and accentuation of landscape entities makes OBIA attractive for the analysis of wetland change; however, to date such applications have been less common than single-date or single-year analyses. Because the availability of suitable imagery is usually temporally discrete, detectable changes between the pairs of dates may often appear "patchy" [23] and thus may be characterized as spatial units, i.e., change objects [39]. Reduction of noise at the object level is also important, as it increases the probability that observed changes indeed result from landscape transformations rather than abnormal pixels and noise. Objects may also provide meaningful spatial basis for assessing surface cover transitions in highly heterogeneous, mixed-cover wetlands. Detecting shifts in "hard" class boundaries in such areas may be problematic; alternatively, local dynamics of surface inundation and phenology may be inferred from changes in class membership values at the level of small primitive objects [7]. A promising, yet under-explored, research strategy is the "object fate analysis" [106] focusing on spatially explicit assessment of change in the object geometry. Such an approach takes into account not only the overall shifts in class sizes, but also spatial arrangement, and therefore, spatial "context" of detected transformations.

Among the reviewed studies performing change analysis, the most common approach to detect transition was spatial overlay of the individual-date classification results [7,59,67,72]. Specific purposes of change assessments varied, including, e.g., the analysis of bush encroachment in a degraded sub-alpine bog in Estonia [67], the study of three-decade transitions in alpine wetlands in Tibet focusing on signals 
of ecological succession and high-altitude climate change [59], the analysis of dominant surface transitions of the largest freshwater wetland in China during the low water season [7], broad-scale analysis of aquatic and terrestrial class shifts in a Canadian peatland landscape [46] and the study of small wetland size change from 1989 to 2005 in the U.S. Prairie Pothole region as a basis for characterizing wetland hydrologic functions [86]. In these studies, OBIA facilitated change detection by alleviating local noise, accounting for wetland textures and providing the basis for delineating wetland bodies and their transitions as landscape entities.

Successful change analysis relies on a key assumption that in order to be detected, the magnitude of transitions should exceed the sizes of individual pixels or even primitive objects; otherwise, the diagnostics of "change" may be limited or obscured by noise [59]. This underscores the importance of image spatial resolution in assessing and interpreting wetland dynamics. Medium and coarse-resolution data may have limited sensitivity to local smaller-size transitions and may be more effective for spatially contiguous cover types, such as glaciers and lake-wetland complexes in [55]. In contrast, high and very high-resolution data may be suitable for detecting fine-scale transitions of wetland components and even distributions of individual species following local hydrological variation and management actions [51]. Some of wetland ecological processes, such as exotic plant species invasions, may be manifested as fine-scale yet rapid incremental changes, and their timely detection may be of critical value for planning, management and conservation [30,34]. Advances in very high-resolution data with pixel size $<1 \mathrm{~m}$ are extremely promising for this task, as shown by the detection of invasive coastal marsh Spartina spp. using UAV-collected imagery in [34].

Finally, a special challenge should be noted for wetlands with high magnitude of short-term variation, where between-date changes may represent both long-term transitions and short-term effects of plant phenology and disturbance [45,53,74,107]. Investigating long-term shifts in such systems requires disentangling surface trends from transient phenomena, and in case of small isolated wetlands - accounting for seasonal hydrological processes that are not entirely "visible" to remote sensors $[16,86]$. The OBIA framework may facilitate alternative approaches in such landscapes using primitive objects as the spatial units of change trajectories. For example, in a dynamic classification of Poyang Lake, China [53] primitive objects were generated at the time of high patchiness at the peak of the low water season and used to map seasonal classes, or "dynamic cover types", as sequences of states and transitions from multi-date images over one flood cycle. The use of dual-date SAR images in the study of Amazon Basin [74] allowed to develop a "vegetative-hydrological classification scheme" accounting for different flood regimes of upland and wetland cover classes; similar approaches were used in other radar-based studies of large and complex inundated tropical landscapes $[75,76]$. These and other studies of dynamic wetland regions $[38,45]$ suggest that prior knowledge about the system phenology and hydrological regimes can be used to constrain change trajectories to physically and ecologically plausible classes, and that OBIA provides important spatial and temporal context for more accurate mapping and interpretation of dynamic regimes while smoothing local noise. 


\section{Factors Affecting the Accuracy of Wetland OBIA Applications}

\subsection{Accuracy in Wetland OBIA}

Given high variability in geometric properties of wetland patches, the assessment of accuracy in reviewed studies focused largely on the match between mapped classes and identities of selected test locations using a traditional confusion matrix. Test samples often represented pixels, or "point" locations [6,39,59], reference plots or ground polygons [23,27,41,43], or primitive objects with known characteristics [7,45,48,51,53]. Several studies used fuzzy accuracy assessment to account for sub-object class mixtures in complex areas $[7,32,48]$. In wetland delineation analyses, alternative measures of accuracy were employed such as proportion of wetlands detected relative to known references [87] or the degree of overlap between mapped and reference wetland polygons, summarized for target classes [27] or ranked wetland size groups $[15,16,18]$. Two studies of the riparian zone in Central Queensland, Australia $[42,88]$ evaluated accuracy as linear coefficients of determination $\left(\mathrm{R}^{2}\right)$ between remotely sensed and field metrics of riparian morphology and plant cover. To overcome common limitations on reference data in wetlands, studies used ancillary information such as regional wetland inventories [86,89], expert interpretation of aerial photos and objective sampling interpolation techniques to select reference data based on spectral similarity with known locations [8,83].
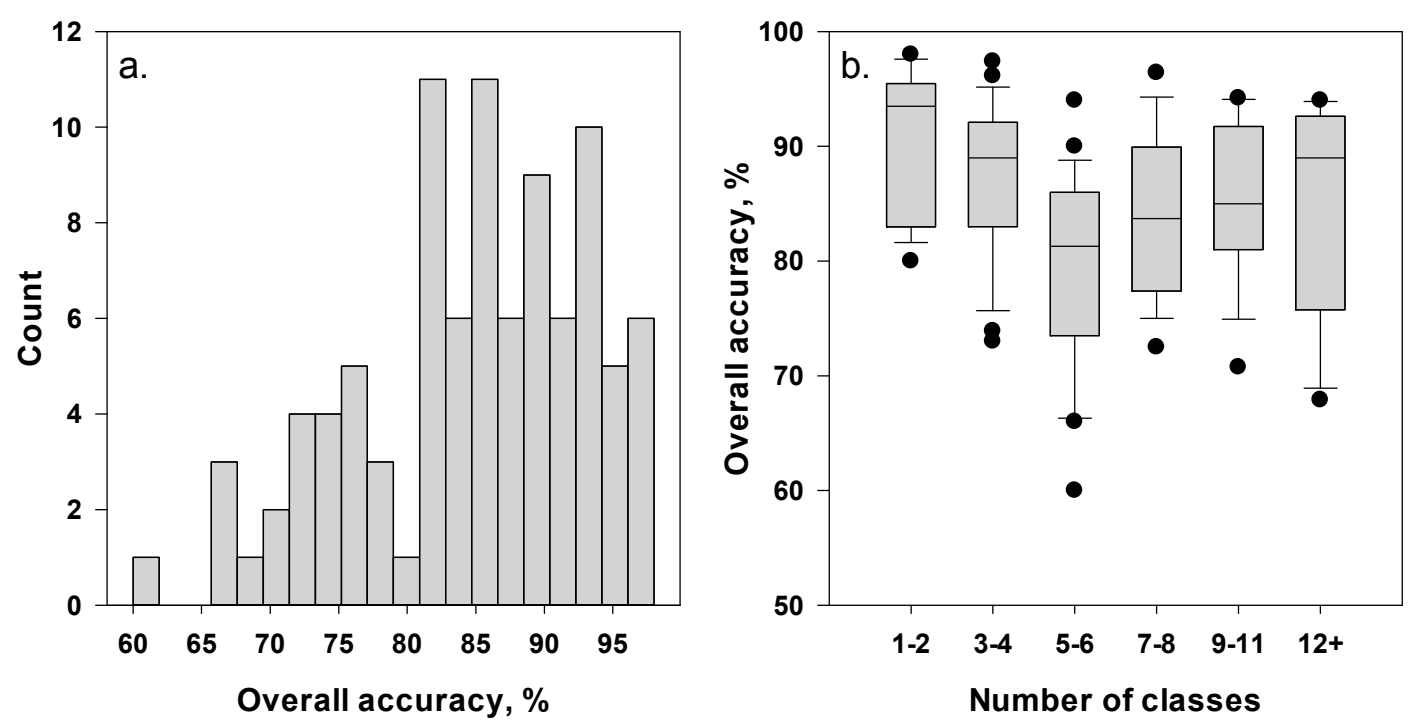

Figure 2. Classification accuracy in the reviewed papers: (a) histogram of the highest overall classification accuracy from 61 reported cases, and (b) distribution of classification accuracies with respect to the number of classes in the scheme (multiple statistics reported in some papers).

Among the reviewed studies, the overall classification or mapping accuracy was reported in 61 cases (Figure 1), and the distribution of the highest values per study or classification level was skewed to the left showing more values on the higher accuracy end, with the mean of $84.6 \%$ and the median of $85.9 \%$ (Figure 2a). No significant correlation was evident between the highest overall accuracy and either spatial resolution or spatial extent ( $p$-value $>0.1$ ) of the study area. Furthermore, the accuracy was not strongly associated with the number of target classes (Figure $2 \mathrm{~b}$ ), and values exceeding $90 \%$ were 
reported with both simple and more complex classification schemes. Generally, the occurrence of accuracies below the $85 \%$ benchmark increased after the number of classes exceeded 4 ; however, very few analyses used more than 10 to 11 classes. One study [8] tested discrimination of larger sets of wetland plant species with advanced machine-learning techniques and reported decline in accuracy from $98 \%$ with 10 classes to $89 \%$ with 40 classes. In addition, four studies compared object-based accuracy to pixel-based classification outcomes and reported the improvement of the overall accuracy by $1.5 \%$ [30], $7 \%$ [22], 28.8\% [29] and 31\% [24] with OBIA relative to the best pixel-based result. However, caution is needed for interpreting such accuracy comparisons, because studies vastly differed not only in their data and methods, but also in the quantity and characteristics of test samples. Furthermore, relatively common post-classification manual editing of OBIA results may increase the final map accuracy but reduce objectivity and clarity on method-specific performance and transferability [50].

These issues raise the questions of how various steps and criteria in OBIA affect the ultimate accuracy and how different studies approached these decisions. The process of OBIA is not fully automated, and its options for user customization may become particularly complex and ramified in wetland analyses. One obvious factor in the classification success concerns conceptual definitions of semantic classes and their feasibility to be discriminated $[17,27,56]$. A number of reviewed studies addressed this challenge by choosing distinctive, albeit sometimes general, wetland cover type definitions [7,13,26,50]; focusing on plant functional types rather than more similar species or communities $[17,39]$ and using temporal (i.e., seasonal) information in class definitions to incorporate phenology and hydrological regimes $[53,74,104]$. The final outcome of OBIA classifications also depends on several other choices that have to be made using quantitative criteria or expert judgment:

- Spatial scale and spectral properties of image data as inputs to segmentation;

- The choice of segmentation parameters to generate objects as classification units;

- The choice of object attributes to discriminate among classes;

- The choice of a classification approach and statistical algorithm.

Below, these choices and associated challenges are discussed from the perspective of the reviewed wetland studies.

\subsection{Spatial Scale of Research Questions and Input Data}

The choice of remote sensing data is critical in the OBIA success, and it typically depends both on the research objectives and on the availability of data of sufficient quality, appropriate spatial scale and affordable cost. The lack of the association between the highest overall accuracy and either spatial extent or image resolution (Figure 1) in the reviewed studies suggests that spatial scale was not a direct constraint on OBIA performance. Rather, it reflected differences in the spatial scope determined by study area size and pixel resolution, and the appropriateness of target classes given the latter. Ideally, image object dimensions should significantly exceed the scales of local noise and irrelevant (i.e., non-textural) heterogeneity $[14,19,20]$. With high-resolution data, this is possible through generation of objects that are relatively large compared to pixel size. With medium and coarse-resolution data, this task becomes less straightforward: while some of the local noise becomes "absorbed" at the pixel level, so do meaningful boundaries and textural properties of classes $[17,43,88]$. 
Among the reviewed papers, studies operating at larger spatial extents often had to use coarser-resolution data of large instantaneous ground coverage, such as 300-m MERIS and 100-m JERS-1 in [73] for $125,000 \mathrm{~km}^{2}$ West Siberian lowland, or 100-m JERS-1 for 1.77 million $\mathrm{km}^{2}$ in the Amazon basin. With such data, minimum mapping units may become too large and more likely to contain class mixtures in heterogeneous areas [82]. Studies operating at these broad spatial scales typically had to rely on ancillary data from Landsat (30 m), ALOS AVNIR (10 m), IKONOS (4 m) and other commercial satellite images or aerial surveys as the source of reference for classification training or validation $[27,61,79,80]$. In turn, among the analyses of moderate-resolution multi-spectral or SAR imagery, the size of study area varied greatly, and the choice of data was often motivated by cloud-free image availability, spatial coverage and affordability (no cost for Landsat). The 10 to $32 \mathrm{~m}$ pixel size was sometimes admitted as too coarse for wetland OBIA due to limited sensitivity to patch boundaries and the chance of mixed pixels $[17,88]$. Yet, for large and less well studied regions, moderate-resolution data often become an optimal, affordable option. To overcome field sampling limitations, studies at these scales also used ancillary high-resolution images for reference, training and validation $[53,72]$.

For the analyses of high and very high resolution aerial and satellite images, the key advantage was high spatial detail revealing object boundaries, patch geometry and texture $[6,12,13,32,50]$. However, within-class heterogeneity and irrelevant features related to shadows and small ground elements may also become accentuated and challenge classifications at these scales [13,45,57]. For instance, in [5] fine-scale variability in wetland species composition was a limitation for a supervised OBIA classification even at 2-cm resolution, invoking substantial manual post-classification edits of the output map. While such efforts can be aided by flexible process trees (such as rule sets in eCognition), overly customized and fine-tuned algorithms may be difficult to apply at other locations and dates $[21,48,50]$. Field access limitations may constrain analyses even at high resolution, and some studies also had to utilize ancillary aerial photos and GIS data for reference and validation [13,49,52].

Finally, interesting challenges with respect to scale arose in studies mapping wetlands of relatively small size $(<1 \mathrm{ha})$ but over large study areas [15,16,18,48,87]. For instance, the effort to map isolated wetlands in a Florida, USA watershed found that larger bodies tended to be delineated more accurately than smaller ones $[15,16]$; however, combination of pan-sharpened Landsat data (15 m) with DEMs from high-resolution contour data allowed for reliable detection of wetlands up to 0.2 ha. Detection of small wetlands over large spatial extents may require the use of multiple images taken at different dates $[32,48,87]$, and differences in surface phenology may limit the applicability of single-date algorithms across the data. Small wetlands are known to provide critical ecological services in human-modified landscapes [86,87]; yet, they are often not well represented in regional inventories and poorly understood from ecological standpoint $[6,87,89]$. Improving the capacity to detect and monitor them is an important task in the face of changes in climate and regional water uses that may be especially facilitated by object-based analyses of high-resolution data [15,26,87].

\subsection{Characteristics of Remote Sensors}

Spectral properties and physical characteristics of the input data strongly affect the success of recovering wetland cover type and patch extents in OBIA. With passive remote sensing, enhanced sensitivity in moisture-sensitive near- and mid-infrared regions (e.g., in Landsat and SPOT sensors) or in the red edge 
zone (Worldview-2,-3) was beneficial for accurate discrimination of wetland vegetation types and wet features in a number of studies $[17,23,81]$. The lack of spectral band representation with certain sensors may be somewhat compensated by the use of spectral indices and band transformations $[7,25,32,39,45]$. Flexible OBIA framework also allows using different spectral enhancements at the steps of segmentation versus object classification; for example, a tidal marsh vegetation study [25] used principal components as inputs to segmentation and band-derived attributes in classification.

Active remote sensors such as radar greatly facilitated object-based class discrimination in areas spanning across gradients of both inundation (from open water to non-flooded upland cover types) and plant morphology (from aquatic plants and short grasses to shrubs and trees) [6,76,78,79]. In particular, multi-seasonal SAR backscattering was beneficial for (1) detecting wetland classes as objects shaped by seasonal inundation extents; (2) enhancing the contrasts among vegetation types based on differences in seasonal canopy development affecting double-bounce scattering and other characteristic canopy responses; and (3) incorporating differences in temporal variation of backscatter as another characteristic of vegetation classes [53,74-76,78]. Given different sensitivities of common radar wavelengths to canopy structure, some studies successfully combined C- and L-band sensors in complex wetland regions, where relative importance of surface scattering, volume scattering and double bounce varied with ecosystem type $[75,76,79,80,103]$. Other important parameters included band polarization, affecting radar scattering intensity following the interactions with wetland surfaces and canopy elements [37,40,54,75], and incidence angle contributing to wave penetration into canopies and thus affecting the strength of specific responses such as double-bounce effect $[37,75]$.

To enhance the information extraction, a number of wetland studies also combined SAR and multi-spectral imagery such as Landsat $[27,47,77,82]$ either as joint inputs to segmentation $[53,71]$ or at different steps of analysis [47,78]. Such data fusion takes advantage of both the spectral contrasts among structurally similar cover types and radar-sensed differences in inundation and vertical canopy structure. However, OBIA results may be sensitive to positioning errors and mismatches in spatial resolution among different sensors [88]. Given the logistical "cost" of pre-processing radar data, it is practical to consider whether expected benefits could be achieved with more readily available data such as Shuttle Radar Topography Mission (SRTM)-based DEMs and water body maps [73,77,80].

Lidar data has been also increasingly used in wetland studies to facilitate discrimination of spectrally similar but structurally different canopies based on architecture and height, such as tall reeds versus shorter marsh vegetation in [32], or riparian areas with vegetation overhang [42,69]. However, these benefits have not been uniform among wetland types. For instance, in a study of a predominantly herbaceous tidal marsh [28], inclusion of lidar did not substantially enhance OBIA accuracy, instead over-simplifying recognizable wetland features and exacerbating over-segmentation of tidal channels. To take greater advantage of lidar information, future applications should test more comprehensive metrics beyond elevation or canopy height alone. Examples of such metrics were demonstrated by a study in Australia using lidar-based datasets as the only input to OBIA in a riparian landscape [42]. Similarly, an object-based wetland delineation study in Minnesota, USA [6] tested several lidar-based landscape metrics to complement spectral information from high-resolution aerial photography; among those, compound topographic index (CTI) was especially useful in discriminating wetland and non-wetland objects at different levels of slope steepness. Because lidar data of sufficiently high point 
density to resolve fine-scale marsh canopy structure are not yet available at large spatial extents, the benefits of this sensor to date have been limited primarily to local and site-specific studies.

Finally, the utility of any data source to OBIA objectives may depend on the timing of data acquisition. For instance, in [26] using color orthophotos the leaf-off winter stage enabled mapping turtle habitat attributes in a forested landscape and delineating wetland boundaries that otherwise would have been obscured by tree canopies. Wetland detection may benefit from high inundation stages; the study of small isolated wetlands in Florida, USA [16] recommended mapping them at the wettest time of the year. Peak times of green vegetation development may result in spectral similarity of plant types, calling instead for dates of phenological contrast such as wet-dry, or leaf on-leaf off stages $[17,32,38,74,75]$. In coastal wetlands, high tidal stages may limit the ability of both active and passive sensors to discriminate wetland classes due to strong effects of water such as absorption in the infrared and microwave regions. In subtropical and tropical zones, multi-date image combinations provide strong basis for separating inundated cover types and accentuate object boundaries [53,74,78]. To facilitate more accurate and reproducible analyses, future studies should more effectively utilize multi-temporal data by considering which hydro-phenological stages provide most information for segmentation and accurate identification of wetland typologies or internal cover types $[45,78]$.

\subsection{The Challenge of Segmentation Parameter Selection}

Segmentation is the key first step in many OBIA analyses, and its outcomes have strong implications on subsequent accuracy and interpretability of results. At present, there is no clear standard for pre-classification assessment of segmentation effects on the final outcomes in either wetlands or other heterogeneous landscapes. In fact, among the reviewed studies, relatively little justification was provided for the choice of segmentation metrics, with trial and error being a common approach, a concern previously discussed in [28]. Simultaneous testing all of the possible segmentation parameters (e.g., combinations of input bands and their weights, scale, compactness, shape, spectral thresholds or all of these) is a complicated task and, regrettably, still not a common practice in OBIA studies. Furthermore, different types of ground objects may be more effectively highlighted with different values of segmentation parameters [28,93], which also complicates the decision about the "optimal" segmentation across multiple research objectives. A notable example of an objective supervised workflow was demonstrated in a non-wetland OBIA application to landslide mapping [108], where multiple segmentation levels were first assessed in terms of their effects on class separability, and then a variable importance measure based on random forests machine-learning method was quantified to select the most informative object attributes for distinguishing landslides.

Several wetland studies also explored specific quantitative and qualitative criteria to determine segmentation parameters while avoiding superfluous subjectivity. These strategies included metrics of within-object homogeneity and spectral contrast to neighbors to determine the scale of primitive objects [7,53], approaches based on local spatial autocorrelation measured by Moran's I of the spectral values [8], also used to optimize segmentation in non-wetland analyses [109], and a set of ranked visual criteria used in [28] to compare segmentations' ability to recover known wetland objects (such as patches, channels and tidal zones). Both these and other studies using trial and error often concluded that spectral information was more important in wetland object delineation than shape, and that smoothness 
and compactness criteria affected the outcome much less strongly than spectral properties. Segmentation parameters greatly varied among all studies.

Although the peaks in classification accuracy at certain object scale were sometimes used to identify important spatial scales in wetlands $[13,17]$, there is a growing consensus that diverse landscape classes may not be always adequately characterized at a single segmentation level $[17,28,95,96]$. For instance, in the study of wetland plant functional types in [17], more narrowly defined plant classes at lower hierarchical level differed in segmentation scales which maximized their individual accuracies. Similarly, in [13] class-specific accuracies of vegetation, water channels and mud reached maximum values at different segmentation scales, and those typically did not match the maximum scale of the overall accuracy. These results suggest that searching for a single "optimal" segmentation may not be a productive goal in complex landscapes, and instead call for new methods to determine and test hierarchical sets of ecologically relevant and spatially linked object levels [23,68]. Examples of such methods that should be more rigorously explored in wetlands may include the abovementioned ESP tool for eCognition [95,96] and the Plateau Objective Function (POF) in [110] based on spatial autocorrelation and within-object variance, which identified segmentation parameters suitable for capturing different-sized landscape features in a complex terrain.

\subsection{The Challenge of Selecting Object Attributes for Classification}

The potential diversity of class-discriminating attributes that can be defined for image objects creates a major challenge of choosing from large number of features, some of which may be redundant [50,53]. This selection becomes even more difficult when specific sets of candidate variables discriminate only particular groups of classes $[49,62]$ or when the study spans over different locations or dates. For instance, in [48], 43 different aerial photos used 43 unique identification procedures to characterize tidal marsh composition. In [50], classification accuracy of a coastal high marsh was higher when rule sets were applied to the images they were developed for, versus other images from the same region. In the studies of long-term change in seagrass and coastal cover types in Australia [21] and alpine wetland transformation in Tibetan plateau [59], rule thresholds and membership functions had to be re-adjusted for different image dates due to spectral inconsistencies among Landsat images. However, the routine need for algorithm re-adjustment or post-classification manual editing [5,59,67,72,74,80,82] may become a serious barrier for repeated monitoring of wetland cover with reproducible algorithms [50].

These challenges call for more rigorous uses of quantitative and objective attribute selection methods, from simple statistical tests for class separability and redundancy among individual correlated attributes, to more advanced machine-learning data mining algorithms that can guided by expert knowledge [108,111]. Several studies pre-tested spectral separability of wetland class samples with various individual object attributes using specialized statistical metrics such as Jeffries-Matusita and Bhattacharyya distances [12,13,37,65,81]. Other studies tested class discrimination with multiple attribute sets using automated computer-based strategies, such as eCognition's [90] feature space optimization tool $[48,57,80,81]$ and machine-learning attribute selection algorithms in the open-source Weka [112] software $[53,87]$. These algorithms provide practical and time-efficient opportunities for testing large sets of diverse candidate variables, and their importance will likely grow with more intensive data 
processing needs and increasingly higher spatial detail [34,35] and temporal frequency [7,53,102] of novel remote sensing instruments.

\subsection{Importance of the Classification Method}

The choice of a specific classification method may strongly affect wetland mapping outcomes with both pixel- and object-based approaches [9-11,17,87]. Most of the reviewed analyses (Figure 3) used either custom knowledge-based rule sets $[26,48,50,84]$, or supervised nearest-neighbor classification in eCognition software which uses estimates class membership values from training samples and assigns classes to unlabeled objects based on fuzzy logic [7,13,16,18,22,24,25,32,53,57,84]. In contrast to pixel-based wetland literature, reviewed studies did not employ unsupervised clustering or statistical ordination techniques at object level, except one study using unsupervised clustering of image regions to obtain wetland and non-wetland mask [74]. Several studies used unsupervised pixel-based classification to generate preliminary cover types and then performed more specific object-based analyses for wetland delineation [86], classification of wetland units [65] or mapping their intrinsic cover types [84,85]. Such hybrid approaches combining pixel and object units were especially useful in complex wetlands with heterogeneous surface cover and fuzzy boundaries.

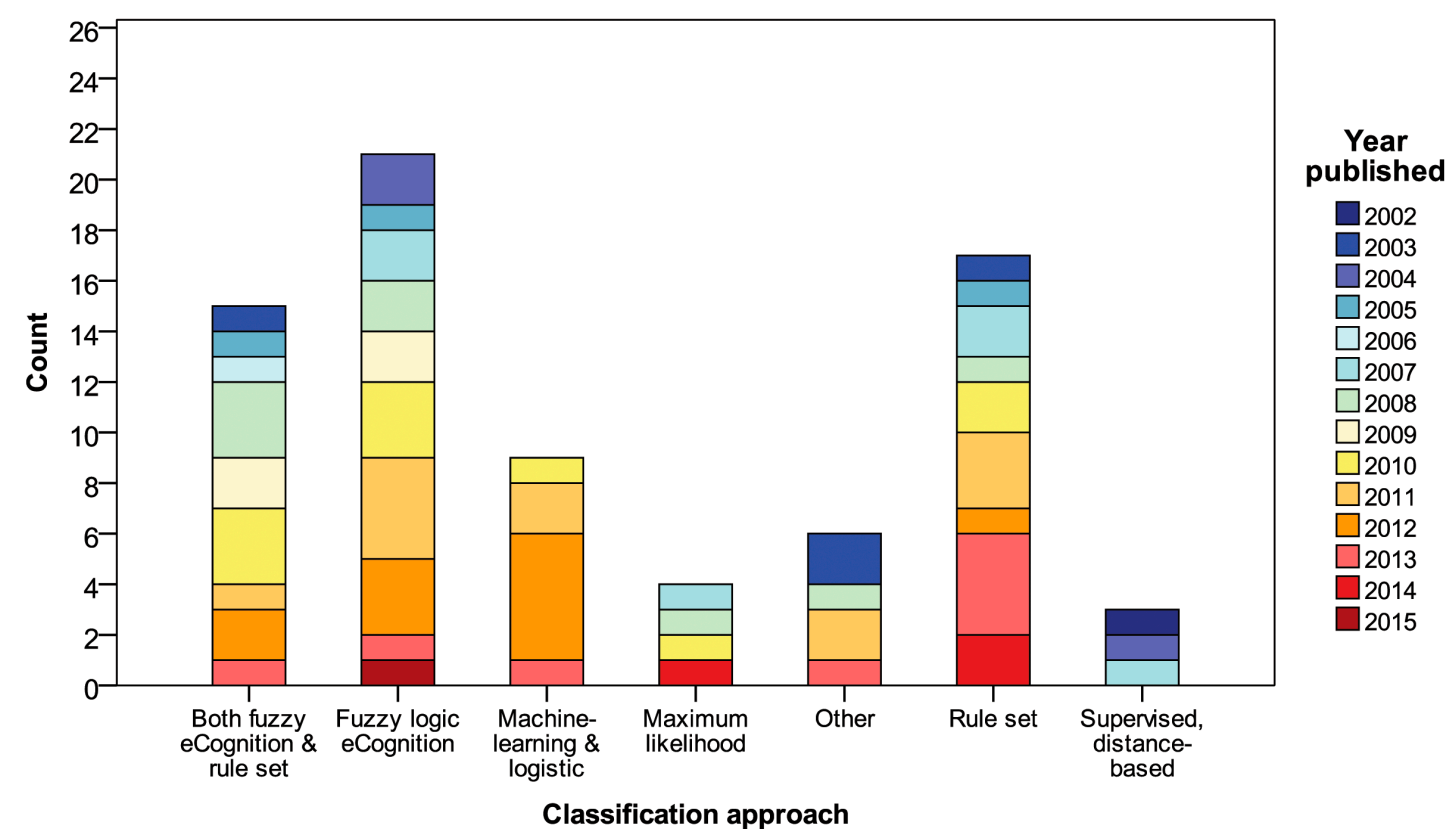

Figure 3. Applications of classification approaches by general method type and publication year.

Among the statistical supervised approaches, various methods were used from conventional maximum likelihood classifiers [58] to novel machine-learning algorithms [8,17,45,81,83,87]. Supervised approaches based on minimum distance in the feature space were more intensively employed at the early stages of wetland OBIA (Figure 3), while recent years have been marked with more active use of machine-learning algorithms. Their potential, however, remains somewhat under-utilized compared to rule-based techniques and eCognition's fuzzy logic classifier [24,25,46,84,90]. In part, this could be explained by the "black box" nature of common machine learning methods and their reliance on iterative learning to improve predictive capacity, which constrains the interpretability of their 
parameters and error in the outcome. Relative performance of various algorithms in wetland setting also remains unclear; few studies have compared multiple techniques for the same objective, and among those which did, similar approaches were ranked differently $[7,83,87]$.

Several machine-learning method families, however, are particularly promising to circumvent the challenges of heterogeneity and limited reference data in wetland OBIA. For example, support vector machine (SVM) methods perform classification by fitting a hyperplane along the class boundaries in the feature space, and therefore may not require training sample sizes as large as methods comparing distances to class means. Superior performance of SVM compared to other popular methods was reported in mapping of wetland plant communities and species in Florida, USA [8], object-based classification of Galapagos mangroves in [81] and the study of wetland plant functional types in Poyang Lake, China [17]. Decision tree learning methods such as classification and regression trees (CART) and random forest have also been successful in wetlands [8,17,88]; in [87], two decision tree methods and k-nearest neighbor (k-NN) classifier surpassed in accuracy logistic regression, SVM and Bayesian algorithms. Neural networks $[17,83,103]$ can be internally customized for complex classification tasks, as demonstrated by $>13 \%$ improvement in accuracy of wetland plant community mapping with new adaptive learning vector quantization neural network compared to minimum distance, maximum likelihood and spectral angle mapper classifiers [83]. Importantly, the success of machine-learning algorithms strongly depends on their parameter specifications, which could partially explain the lack of consensus on their relative performance. Pre-classification testing for the optimal parameters should be an integral part of their use, such as the "grid search" for controls on decision margin and error penalty in SVM [102], the number of hidden layers in neural networks or limits on regression tree "growth" and "pruning" in decision tree approaches [44].

Method specifications and the order of their implementation become particularly important in hierarchical and stepwise OBIA $[23,25]$. While accuracy is often assessed at the final map stage, errors at individual steps, threshold rules and hierarchical levels may accumulate and disproportionately contribute to final accuracy values. Furthermore, classifications schemes are often designed based on the expected hierarchical relationships among land cover types and management units [27], ecological hierarchies in vegetation communities [17,25], topography and hydrology [13,68], but not as often with spectral characteristics and spatial attributes ultimately affecting class separability in given data. More profound understanding of the sources and pathways of error propagation in multi-step wetland analyses is necessary to inform hierarchical studies and more effectively reconcile ground-based structure of landscape entities with their optical properties [113].

\section{Conclusions}

\subsection{Key Summary Points from the Reviewed Studies}

It is evident from the reviewed studies that OBIA framework offers several important advantages to wetland analyses in various regions of the world, and its use as a flexible, multi-scale approach will likely actively continue in these complex and diverse environments. However, it is also obvious that the progress in applications and further improvement of delineation and classification accuracies are 
currently hampered by wetland surface complexity, dynamics and by the shortcomings in OBIA implementation. Several collective conclusions follow from the synthesis of reviewed papers.

1. OBIA is useful for alleviating local spatial heterogeneity of wetland cover as a "smart filtering" strategy, particularly with high and very high resolution data. Integrating pixel signals at the scale of image objects allows smoothing some of the local noise and accentuating spectral contrasts among the target cover types. This advantage becomes especially important for resolving fine-scale wetland composition with high-resolution data, where high local variation in pixel values may be caused by the detail on structural and ecological vegetation properties, shading and small ground surface elements. Furthermore, reducing local heterogeneity does not require an exclusive match between semantic "ground" objects and the segmentation output; on the contrary, it is often achieved by the use of small primitive objects that "absorb" local noise or spatial autocorrelation and serve as mapping units to recover larger patches through classification.

2. OBIA is useful for mapping isolated wetlands as semantic objects. The object-based framework is useful for capturing the contrast in topographic, hydrological, geometric and ecological characteristics between wetland units and their landscape matrix, either based on image spectral data alone, or using ancillary geospatial information. This allows delineating whole wetlands as landscape entities and makes OBIA especially useful for studying small, hard-to-detect isolated wetlands scattered in mixed-cover landscapes [6,26,86,87].

3. OBIA framework facilitates hierarchical approaches to detection and classification of wetland ecosystems and their components. Creating spatially linked nested object layers allows preserving object boundaries at different classification and analysis levels and controlling for the effects of the outlying pixels. In wetland studies, this capacity allows to build multi-step analyses, often starting by separating wetlands from other landscape cover types and then characterizing their nested cover types and habitat elements using topographic, hydrological and vegetation-based strata. This strategy allows resolving specific confusions among classes individually and incorporating expert knowledge and ancillary data into the analysis. However, it is likely that classification error accumulates when classification results from one hierarchical level are used as the input to steps at the next level. Such error propagation has not been investigated extensively and calls for more efforts to determine its effects on classification uncertainty.

4. Flexibility of the OBIA framework is coupled with the risk of overly subjective algorithms that may be difficult to validate, reproduce or generalize. Flexible implementation of OBIA algorithms enables the researcher to develop custom procedures adaptable to the study objectives and specifics of a given landscape. However, different stages of the analysis require decisions on input datasets, segmentation parameters, discriminating attributes and classification methods that may be difficult to pre-test in their entirety. To narrow down the options, OBIA studies often have to rely on prior knowledge of the landscape and expert judgment, which may introduce subjective biases. To reduce the effect of subjectivity while preserving the contribution of expert knowledge, future studies should more rigorously utilize statistical and machine-learning techniques in attribute selection and classification to explore candidate methodologies with lower cost of time and labor.

5. The capacity to use OBIA to monitor wetland change and long-term dynamics is still under-developed compared to strategies for single-date or same-year seasonal analyses. Most of the 
reviewed studies applied OBIA to produce "static" classifications and maps, using either single-date data or multi-temporal images highlighting class differences in surface phenology. In contrast, applications of OBIA to wetland dynamics are still relatively few, conducted mainly as post-classification overlay of mapped cover type extents. Quantifying wetland change from such analyses is likely to be affected by segmentation and classification inaccuracies at individual dates. An under-explored but promising alternative strategy is to trace the "fate" of object geometry and spatial context relationships [106]. Advancing this technique in wetlands would enable novel approaches to modeling their dynamics and uncovering the drivers of their landscape processes.

6. A number of wetland-specific challenges to remote sensing-based landscape inference remain important concerns in OBIA, despite its ability to alleviate local surface heterogeneity and reduce "salt-and-pepper" speckle. Spectral similarity of diverse classes due to homogenizing effects of moisture or dead vegetation signals may reduce classification accuracy and the effectiveness of class discrimination. In highly diverse mixed-community wetlands, subpixel heterogeneity, mixing of class signals and dilution of fine morphological features limits separability of cover types even at very high spatial resolutions of the input data $[5,22,88]$. Difficulties in field access and mobility often constrain the feasible scope of field sampling $[7,32]$ and thus may limit sample representativeness for classification training and testing [51]. Advances in very high resolution and near-surface remote sensing are promising for resolving these issues by providing more detailed and comprehensive descriptions of wetland surfaces and enabling more effective use of texture to discriminate classes based on spatial structure and intrinsic patterns.

\subsection{Future Research Needs for OBIA in Wetlands}

Cumulative evidence from the reviewed literature suggests several important directions to strengthen and expand the potential of OBIA in wetland analysis and monitoring. First, there is an urgent need for more automated and user-friendly strategies to navigate rich datasets and facilitate objective choices of parameters and techniques at different stages of the OBIA process. Complexity of wetland composition and the lack of prior ground knowledge may limit the expert's ability to make accurate judgments on the most appropriate segmentation and classification outcomes, thus calling for more rigorous data mining approaches, recognition systems and attribute selection. In turn, more targeted testing and comparisons of the new machine-learning methods are needed to better elucidate their relative performance and to establish clearer standards and strategies for pre-testing their key parameters. To fulfill these recommendations, more training, education and potentially stronger partnerships with computer scientists and statisticians would be needed on the researcher's side.

Second, more automated tools and parameterization are needed specifically for high-resolution delineation and monitoring of wetland vegetation within landscape extents that are too large or too inaccessible for comprehensive field surveys. Particularly important tasks include assessing plant establishment at early stages of wetland restoration [3], detecting spread of invasive species [34] and improving the accuracy of wetland mapping for valuation of ecosystem services and budgeting for restoration and management actions [52]. Applications of OBIA to these novel questions are currently limited by the lack of guiding standards and tools for objective, data-driven selection of image segmentation parameters and by the challenges of transferring algorithms across locations and dates [48,50]. Specific 
recommendations include: (1) more rigorous comparative testing of the unsupervised indicators of ecologically relevant segmentation scales such as local variance in the ESP tool $[95,96]$ or objective functions [110]; (2) more wetland-specific comparisons of segmentation method performance to inform technique selection and parameterization; and (3) developing guiding standards on acquiring and pre-processing input image data to maximize spectral and phenological contrasts between target classes and their landscape matrix and to reduce the chance of fuzzy boundaries.

Third, to facilitate more comprehensive object-based analyses of wetlands with complementary remote sensors (such as passive multi-spectral and active radar and/or lidar), more consistent and robust strategies are needed to generate multi-dimensional objects from the inputs and to validate their ecological relevance for a given application. For wetlands, an especially promising direction is the 3D representation of spatial hydro-ecological and vegetation units as landscape "objects" [69], similar to terrestrial "LIDARScapes" concept [114]. Such representations would greatly facilitate not only mapping, but also modeling of wetland ecosystem processes such as transfer of solar radiation in canopies affecting seasonal dynamics of plant biomass and photosynthesis, habitat properties for canopy-dwelling wildlife and monitoring of broader-scale hydro-ecological zones within complex marshlands. Rapidly developing theory and tools for lidar-based 3D ecosystem modeling in forested and other upland ecosystems [88,114-117] offer useful prototype strategies that should be adapted for similar analyses in wetland settings.

Fourth, there is an urgent need to strengthen OBIA applications to the analyses of wetland change. Many wetland regions globally are experiencing rapid transformations such as alpine wetlands affected by melting of glaciers and climatic shifts in high-altitude regions [55,59], tropical wetlands altered by drought [78] and deforestation [39,82], coastal systems threatened by sea level rise [98] or, conversely, declining water levels [49], and marshes invaded by exotic species [30,34,57]. Accurate assessment of these changes is critical for research, planning, management and restoration; yet, commonly used post-classification change detection approaches may suffer from error at individual dates. Given the discrete-time availability of remote sensing data, new strategies are needed to detect the changes as processes and regimes [7,74] and to track the "fate" of landscape entities over time [106]. The success of such approaches is likely to be contingent on accurate, data-driven object detection and delineation, calling again for more effective automated tools for specific method and parameter selection.

Finally, the potential of OBIA should be more rigorously utilized in wetland ecosystem ecology beyond cover type mapping and change detection alone. In particular, hierarchical OBIA is promising for multi-scale analyses of ecosystem structure and function and their scaling from patch levels to broader spatial extents [70,78]. For instance, benefits of objects over pixels as spatial units for empirical modeling of vegetation parameters such as biomass and canopy properties have been shown for upland forests [118,119]; however, in wetlands, such analyses are yet to be developed. Even prior to active use of the OBIA framework, ecologists have discussed hierarchical organization of landscape ecosystems as spatially nested "objects" shaped by regional climate, landforms, vegetation, disturbance and other factors [120-122]. These developments produced several efforts to characterize and document landscape ecosystems, including wetlands [123], in the Upper Great Lakes Region [121,124], at the time relying heavily on intensive field surveys and manual mapping. Advances in GIS, remote sensing and hierarchical OBIA offer new cost-effective venues to reproduce such analyses in other regions and to use them repeatedly to assess ecosystem changes following climatic, successional and land use 
transformations. These efforts would call for stronger theoretical linkages between the analyses of spectral data and ground knowledge of ecological and physical processes; however, the basis for these linkages has been already growing as shown by innovative OBIA applications in geomorphology and ecosystem studies [20,108,110,118,125-127]. Continuing efforts to combine ecological, geographic and spectral information via hierarchically organized landscape framework would be of great utility to studies of pressing ecological questions in wetlands, taking them to the new levels of spatio-temporal research inquiry.

\section{Acknowledgments}

This literature synthesis was prepared as part of a research study funded by the Delta Science/California Sea Grant Fellowship number R/SF-52.

\section{Conflicts of Interest}

The author declares no conflict of interest.

\section{References}

1. Zedler, J. B.; Kercher, S. Wetland resources: Status, trends, ecosystem services, and restorability. Annu. Rev. Environ. Resour. 2005, 30, 39-74.

2. Mcleod, E.; Chmura, G.L.; Bouillon, S.; Salm, R.; Bjork, M.; Duarte, C.M.; Lovelock, C.E.; Schlesinger, W.H.; Silliman, B.R. A blueprint for blue carbon: toward an improved understanding of the role of vegetated coastal habitats in sequestering CO2. Front. Ecol. Environ. 2011, 9, 552-560.

3. Klemas, V. Using remote sensing to select and monitor wetland restoration sites: An overview. J. Coast. Res. 2013, 29, 958-970.

4. Belluco, E.; Camuffo, M.; Ferrari, S.; Modenese, L.; Silvestri, S.; Marani, A.; Marani, M. Mapping salt-marsh vegetation by multispectral and hyperspectral remote sensing. Remote Sens. Environ. 2006, 105, 54-67.

5. Yoshino, K.; Kawaguchi, S.; Kanda, F.; Kushida, K.; Tsai, F. Very high resolution plant community mapping at High Moor, Kushiro Wetland. Photogramm. Eng. Remote Sens. 2014, 80, 895-905.

6. Rampi, L.P.; Knight, J.F.; Pelletier, K.C. Wetland mapping in the Upper Midwest United States: An object-based approach integrating LiDAR and imagery data. Photogramm. Eng. Remote Sens. 2014, 80, 439-448.

7. Dronova, I.; Gong, P.; Wang, L. Object-based analysis and change detection of major wetland cover types and their classification uncertainty during the low water period at Poyang Lake, China. Remote Sens. Environ. 2011, 115, 3220-3236.

8. Zhang, C.; Xie, Z. Object-based vegetation mapping in the Kissimmee River watershed using HyMap data and machine learning techniques. Wetlands 2013, 33, 233-244.

9. Rundquist, D.; Narumalani, S.; Narayanan, R. A review of wetlands remote sensing and defining new considerations. Remote Sens. Rev. 2001, 20, 207-226. 
10. Ozesmi, S.L.; Bauer, M.E. Satellite remote sensing of wetlands. Wetl. Ecol. Manag. 2002, 10, 381-402.

11. Adam, E.; Mutanga, O.; Rugege, D. Multispectral and hyperspectral remote sensing for identification and mapping of wetland vegetation: A review. Wetl. Ecol. Manag. 2010, 18, 281-296.

12. Wang, L.; Sousa, W.P.; Gong, P. Integration of object-based and pixel-based classification for mapping mangroves with IKONOS imagery. Int. J. Remote Sens. 2004, 25, 5655-5668.

13. Kim, M.; Warner, T.A.; Madden, M.; Atkinson, D.S. Multi-scale GEOBIA with very high spatial resolution digital aerial imagery: Scale, texture and image objects. Int. J. Remote Sens. 2011, 32, 2825-2850.

14. Burnett, C.; Blaschke, T. A multi-scale segmentation/object relationship modelling methodology for landscape analysis. Ecol. Model. 2003, 168, 233-249.

15. Reif, M.; Frohn, R.C.; Lane, C.R.; Autrey, B. Mapping isolated wetlands in a Karst landscape: GIS and remote sensing methods. Gisci. Remote Sens. 2009, 46, 187-211.

16. Frohn, R.C.; Reif, M.; Lane, C.; Autrey, B. Satellite remote sensing of isolated wetlands using object-oriented classification of Landsat-7 data. Wetlands 2009, 29, 931-941.

17. Dronova, I.; Gong, P.; Clinton, N.E.; Wang, L.; Fu, W.; Qi, S.; Liu, Y. Landscape analysis of wetland plant functional types: The effects of image segmentation scale, vegetation classes and classification methods. Remote Sens. Environ. 2012, 127, 357-369.

18. Frohn, R.C.; Autrey, B.C.; Lane, C.R.; Reif, M. Segmentation and object-oriented classification of wetlands in a karst Florida landscape using multi-season Landsat-7 ETM+ imagery. Int. J. Remote Sens. 2011, 32, 1471-1489.

19. Blaschke, T.; Strobl, J. What's wrong with pixels? Some recent developments interfacing remote sensing and GIS. Geo. Inf. Syst. 2001, 14, 12-17.

20. Blaschke, T. Object based image analysis for remote sensing. ISPRS J. Photogramm. Remote Sens. 2010, 65, 2-16.

21. Lyons, M.B.; Phinn, S.R.; Roelfsema, C.M. Long term land cover and seagrass mapping using Landsat and object-based image analysis from 1972 to 2010 in the coastal environment of South East Queensland, Australia. ISPRS J. Photogramm. Remote Sens. 2012, 71, 34-46.

22. Kamal, M.; Phinn, S. Hyperspectral data for mangrove species mapping: A comparison of pixel-based and object-based approach. Remote Sens. 2011, 3, 2222-2242.

23. Krause, G.; Bock, M.; Weiers, S.; Braun, G. Mapping land-cover and mangrove structures with remote sensing techniques: A contribution to a synoptic GIS in support of coastal management in North Brazil. Environ. Manage. 2004, 34, 429-440.

24. Myint, S.W.; Giri, C.P.; Wang, L.; Zhu, Z.; Gillette, S.C. Identifying mangrove species and their surrounding land use and land cover classes using an object-oriented approach with a lacunarity spatial measure. GISci. Remote Sens. 2008, 45, 188-208.

25. Tuxen, K.; Kelly, M. Multi-scale functional mapping of tidal wetlands: An object-based approach. In Object-based Image Analysis: Spatial Concepts for Knowledge Driven Remote Sensing Applications; Springer, Berlin, Germany, 2008; pp. 415-412.

26. Barker, R.; King, D.J. Blanding's turtle (Emydoidea blandingii) potential habitat mapping using aerial orthophotographic imagery and object based classification. Remote Sens. 2012, 4, 194-219. 
27. Grenier, M.; Demers, A.-M.; Labrecque, S.; Benoit, M.; Fournier, R.A.; Drolet, B. An object-based method to map wetland using RADARSAT-1 and Landsat ETM images: Test case on two sites in Quebec, Canada. Can. J. Remote Sens. 2007, 33, S28-S45.

28. Moffett, K.B.; Gorelick, S.M. Distinguishing wetland vegetation and channel features with object-based image segmentation. Int. J. Remote Sens. 2013, 34, 1332-1354.

29. Harken, J.; Sugumaran, R. Classification of Iowa wetlands using an airborne hyperspectral image: A comparison of the spectral angle mapper classifier and an object-oriented approach. Can. J. Remote Sens. 2005, 31, 167-174.

30. Laba, M.; Blair, B.; Downs, R.; Monger, B.; Philpot, W.; Smith, S.; Sullivan, P.; Baveye, P.C. Use of textural measurements to map invasive wetland plants in the Hudson River National Estuarine Research Reserve with IKONOS satellite imagery. Remote Sens. Environ. 2010, 114, 876-886.

31. Hussain, M.; Chen, D.; Cheng, A.; Wei, H.; Stanley, D. Change detection from remotely sensed images: From pixel-based to object-based approaches. ISPRS J. Photogramm. Remote Sens. 2013, 80, 91-106.

32. Gilmore, M.S.; Wilson, E.H.; Barrett, N.; Civco, D.L.; Prisloe, S.; Hurd, J.D.; Chadwick, C. Integrating multi-temporal spectral and structural information to map wetland vegetation in a lower Connecticut River tidal marsh. Remote Sens. Environ. 2008, 112, 4048-4060.

33. Watts, A.C.; Ambrosia, V.G.; Hinkley, E.A. Unmanned aircraft systems in remote sensing and scientific research: Classification and considerations of use. Remote Sens. 2012, 4, 1671-1692.

34. Wan, H.; Wang, Q.; Jiang, D.; Fu, J.; Yang, Y.; Liu, X. Monitoring the invasion of spartina alterniflora using very high resolution unmanned aerial vehicle imagery in Beihai, Guangxi (China). Sci. World J. 2014, doi: 10.1155/2014/638296.

35. Anderson, K.; Gaston, K.J. Lightweight unmanned aerial vehicles will revolutionize spatial ecology. Front. Ecol. Environ. 2013, 11, 138-146.

36. Cowardin, L.M.; Carter, V.; Golet, F.C.; LaRoe, E.T. Classification of Wetlands and Deepwater Habitats of the United States; Report No. FWS/OBS/-79/31; U.S. Fish and Wildlife Service: Washington, DC, USA, 1979.

37. Rover, J.; Wright, C.K.; Jr, N.H.E.; Mushet, D.M.; Wylie, B.K. Classifying the hydrologic function of prairie potholes with remote sensing and GIS. Wetlands 2011, 31, 319-327.

38. Conchedda, G.; Durieux, L.; Mayaux, P. An object-based method for mapping and change analysis in mangrove ecosystems. ISPRS J. Photogramm. Remote Sens. 2008, 63, 578-589.

39. Connolly, J.; Holden, N.M. Object oriented classification of disturbance on raised bogs in the Irish Midlands using medium- and high-resolution satellite imagery. Ir. Geogr. 2011, 44, 111-135.

40. Santiago, F.F.D.; Kovacs, J.M.; Lafrance, P. An object-oriented classification method for mapping mangroves in Guinea, West Africa, using multipolarized ALOS PALSAR L-band data. Int. J. Remote Sens. 2013, 34, 563-586.

41. Hess, L.L.; Melack, J.M.; Novo, E.M.L.M.; Barbosa, C.C.F.; Gastil, M. Dual-season mapping of wetland inundation and vegetation for the central Amazon basin. Remote Sens. Environ. 2003, 87, 404-428. 
42. Hurd, J.D.; Civco, D.L.; Gilmore, M.S.; Prisloe, S.; Wilson, E.H. Tidal Wetland Classification from LANDSAT Imagery Using An Integrated Pixel-Based and Object-Based Classification approach. Available online: http://clear.uconn.edu/publications/research/tech_papers/Hurd_et_al_ASPRS 2006.pdf (accessed on 12 March 2015).

43. Hurd, J.D.; Civco, D.L.; Gilmore, M.S.; Prisloe, S.; Wilson, E.H. Coastal Marsh Characterization Using Satellite Remote Sensing and In Situ Radiometry Data: Preliminary Results. Available online: $\quad$ http://www.researchgate.net/profile/Martha_Gilmore/publication/228920465_ Coastal_marsh_characterization_using_satellite_remote_sensing_and_in_situ_radiometry_data_ Preliminary_results/links/02e7e52b9e87c974dd000000.pdf (accessed on 12 March 2015).

44. Canisius, F.; Turral, H.; Mbilinyi, B.P. Analysis of seasonal land use in Usangu wetlands, Tanzania: an object-oriented technique for multi-temporal analysis with high-resolution data. Int. J. Remote Sens. 2011, 32, 1885-1900.

45. Chettri, N.; Uddin, K.; Chaudhary, S.; Sharma, E. Linking spatio-temporal land cover change to biodiversity conservation in the Koshi Tappu Wildlife Reserve, Nepal. Diversity 2013, 5, 335-351.

46. Richmond, O.M.W. Inferring Ecological Relationships from Occupancy Patterns for California Black Rails in the Sierra Nevada Foothills. Available online: http://escholarship.org/ uc/item/43c0173m (accessed on 12 March 2015).

47. Yang, R.-M.; An, R.; Wang, H.-L.; Chen, Z.-X.; Quaye-Ballard, J. Monitoring wetland changes on the source of the three rivers from 1990 to 2009, Qinghai, China. IEEE J. Sel. Top. Appl. Earth Obs. Remote Sens. 2013, 6, 1817-1824.

48. Durieux, L.; Kropacex, J.; Grandi, G.D.D.; Achard, F. Object-oriented and textural image classification of the Siberia GBFM radar mosaic combined with MERIS imagery for continental scale land cover mapping. Int. J. Remote Sens. 2007, 28, 4175-4182.

49. Bock, M. Remote sensing and GIS-based techniques for the classification and monitoring of biotopes. Case examples for a wet grass- and moor land area in Northern Germany. J. Nat. Conserv. Jena 2003, 11, 145-155.

50. Burnett, C.; Aaviksoo, K.; Lang, S.; Langanke, T.; Blaschke, T. An object-based methodology for mapping mires using high resolution imagery. In Proceedings of the International Conference on Ecohydrological Processes in Northern Wetlands, Tallinn, Estonia. 30 June-4 July 2003.

51. Evans, T.L.; Costa, M. Landcover classification of the Lower Nhecolandia subregion of the Brazilian Pantanal Wetlands using ALOS/PALSAR, RADARSAT-2 and ENVISAT/ASAR imagery. Remote Sens. Environ. 2013, 128, 118-137.

52. Evans, T.L.; Costa, M.; Telmer, K.; Silva, T.S.F. Using ALOS/PALSAR and RADARSAT-2 to map land cover and seasonal inundation in the Brazilian Pantanal. IEEE J. Sel. Top. Appl. Earth Obs. Remote Sens. 2010, 3, 560-575.

53. Grenier, M.; Labrecque, S.; Garneau, M.; Tremblay, A. Object-based classification of a SPOT-4 image for mapping wetlands in the context of greenhouse gases emissions: the case of the Eastmain region, Quebec, Canada. Can. J. Remote Sens. 2008, 34, S398-S413.

54. Westra, T.; Wulf, R.D.; Coillie, F.V.; Crabbe, S. Optimal Envisat advanced synthetic aperture radar image parameters for mapping and monitoring Sahelian floodplains. J. Appl. Remote Sens. 2010, 4, 043511. 
55. Powers, R.P.; Hay, G.J.; Chen, G. How wetland type and area differ through scale: A GEOBIA case study in Alberta's Boreal Plains. Remote Sens. Environ. 2012, 117, 135-145.

56. Heumann, B.W. An object-based classification of mangroves using a hybrid decision tree-support vector machine approach. Remote Sens. 2011, 3, 2440-2460.

57. Dronova, I.; Gong, P.; Wang, L.; Zhong, L. Mapping dynamic cover types in a large seasonally flooded wetland using extended principal component analysis and object-based classification. Remote Sens. Environ. 2015, 158, 193-206.

58. Allard, M.; Fournier, R.A.; Grenier, M.; Lefebvre, J.; Giroux, J.-F. Forty years of change in the Bulrush Marshes of the St. Lawrence Estuary and the impact of the Greater Snow Goose. Wetlands 2012, 32, 1175-1188.

59. Arroyo, L.A.; Johansen, K.; Armston, J.; Phinn, S. Integration of LiDAR and QuickBird imagery for mapping riparian biophysical parameters and land cover types in Australian tropical savannas. For. Ecol. Manag. 2010, 259, 598-606.

60. Costa, M.P.F. Use of SAR satellites for mapping zonation of vegetation communities in the Amazon floodplain. Int. J. Remote Sens. 2004, 25, 1817-1835.

61. Costa, M.P.F.; Niemann, O.; Novo, E.; Ahern, F. Biophysical properties and mapping of aquatic vegetation during the hydrological cycle of the Amazon floodplain using JERS-1 and Radarsat. Int. J. Remote Sens. 2002, 23, 1401-1426.

62. Dribault, Y.; Chokmani, K.; Bernier, M. Monitoring seasonal hydrological dynamics of minerotrophic peatlands using multi-date GeoEye-1 very high resolution imagery and object-based classification. Remote Sens. 2012, 4, 1887-1912.

63. Hamilton, S.K.; Kellndorfer, J.; Lehner, B.; Tobler, M. Remote sensing of floodplain geomorphology as a surrogate for biodiversity in a tropical river system (Madre de Dios, Peru). Geomorphology 2007, 89, 23-38.

64. Midwood, J.D.; Chow-Fraser, P. Mapping floating and emergent aquatic vegetation in coastal wetlands of Eastern Georgian Bay, Lake Huron, Canada. Wetlands 2010, 30, 1141-1152.

65. Nascimento, W.R.; Filho, P.W.M.S.; Proisy, C.; Lucas, R.M.; Rosenqvist, A. Mapping changes in the largest continuous Amazonian mangrove belt using object-based classification of multisensor satellite imagery. Estuar. Coast. Shelf Sci. 2013, 117, 83-93.

66. Ouyang, Z.-T.; Zhang, M.-Q.; Xie, X.; Shen, Q.; Guo, H.-Q.; Zhao, B. A comparison of pixel-based and object-oriented approaches to VHR imagery for mapping saltmarsh plants. Ecol. Inform. 2011, 6, 136-146.

67. Rokitnicki-Wojcik, D.; Wei, A.; Chow-Fraser, P. Transferability of object-based rule sets for mapping coastal high marsh habitat among different regions in Georgian Bay, Canada. Wetl. Ecol. Manag. 2011, 19, 223-236.

68. Zhang, C.; Xie, Z. Combining object-based texture measures with a neural network for vegetation mapping in the Everglades from hyperspectral imagery. Remote Sens. Environ. 2012, 124, 310-320.

69. Wagner, I. The Danube Floodplain National Park Habitats-Application of the Object-Based Image Analysis Approach. Available online: http:/www.researchgate.net/publication/ 210286848_The_Danube_Floodplain_National_Park_Habitats_Application_of_the_Objectbased_Image_Analysis_approach (accessed on 12 March 2015). 
70. Gergel, S.E.; Stange, Y.; Coops, N.C.; Johansen, K.; Kirby, K.R. What is the value of a good map ? An example using high spatial resolution imagery to aid riparian restoration. Ecosystems 2007, 10, 688-702.

71. Straatsma, M.W.; Baptist, M.J. Floodplain roughness parameterization using airborne laser scanning and spectral remote sensing. Remote Sens. Environ. 2008, 112, 1062-1080.

72. Nie, Y.; Li, A. Assessment of alpine wetland dynamics from 1976-2006 in the Vicinity of Mount Everest. Wetlands 2011, 31, 875-884.

73. Langanke, T.; Burnett, C.; Lang, S. Assessing the mire conservation status of a raised bog site in Salzburg using object-based monitoring and structural analysis. Landsc. Urban Plan. 2007, 79, $160-169$.

74. Dissanska, M.; Bernier, M.; Payette, S. Object-based classification of very high resolution panchromatic images for evaluating recent change in the structure of patterned peatlands. Can. J. Remote Sens. 2009, 35, 189-215.

75. Tian, B.; Zhou, Y.; Zhang, L.; Yuan, L. Analyzing the habitat suitability for migratory birds at the Chongming DOngtan Natrue Reserve in Shanghai, China. Estuar. Coast. Shelf Sci. 2008, 80, 296-302.

76. Dong, Z.; Wang, Z.; Liu, D.; Li, L.; Ren, C.; Tang, X.; Jia, M.; Liu, C. Assessment of habitat suitability for waterbirds in the West Songnen Plain, China, using remote sensing and GIS. Ecol. Eng. 2013, 55, 94-100.

77. Suchenwirth, L.; Foerster, M.; Cierjacks, A.; Lang, F.; Kleinschmit, B. Knowledge-based classification of remote sensing data for the estimation of below- and above-ground organic carbon stocks in riparian forests. Wetl. Ecol. Manag. 2012, 20, 151-163.

78. Silva, T.S.F.; Costa, M.P.F.; Melack, J.M. Spatial and temporal variability of macrophyte cover and productivity in the eastern Amazon floodplain: A remote sensing approach. Remote Sens. Environ. 2010, 114, 1998-2010.

79. Johansen, K.; Arroyo, L.A.; Armston, J.; Phinn, S.; Witte, C. Mapping riparian condition indicators in a sub-tropical savanna environment from discrete return LiDAR data using object-based image analysis. Ecol. Indic. 2010, 10, 796-807.

80. Johansen, K.; Phinn, S.; Witte, C. Mapping of riparian zone attributes using discrete return LiDAR, QuickBird and SPOT-5 imagery: Assessing accuracy and costs. Remote Sens. Environ. 2010, 114, 2679-2691.

81. Franke, J.; Navratil, P.; Keuck, V.; Peterson, K.; Siegert, F. Monitoring fire and selective logging activities in tropical peat swamp forests. IEEE J. Sel. Top. Appl. Earth Obs. Remote Sens. 2012, 5, 1811-1820.

82. Phua, M.-H.; Tsuyuki, S.; Lee, J.S.; Sasakawa, H. Detection of burned peat swamp forest in a heterogeneous tropical landscape: A case study of the Klias Peninsula, Sabah, Malaysia. Landsc. Urban Plan. 2007, 82, 103-116.

83. Shen, G.; Guo, H.; Liao, J. Object oriented method for detection of inundation extent using multi-polarized synthetic aperture radar image. J. Appl. Remote Sens. 2008, 2, doi:10.1117/1.2911669.

84. Stankiewicz, K.; Dabrowska-Zielinska, K.; Gruszczynska, M.; Hoscilo, A. Mapping vegetation of a wetland ecosystem by fuzzy classification of optical and microwave satellite images supported by various ancillary data. Remote Sens. Agric. Ecosyst. Hydrol. 2003, 4879, 352-361. 
85. Li, J.H.; Chen, W.J. A rule-based method for mapping Canada's wetlands using optical, radar and DEM data. Int. J. Remote Sens. 2005, 26, 5051-5069.

86. Baschuk, M.S.; Ervin, M.D.; Clark, W.R.; Armstrong, L.M.; Wrubleski, D.A.; Goldsborough, G.L. Using Satellite imagery to assess macrophyte response to water-level manipulations in the Saskatchewan River Delta, Manitoba. Wetlands 2012, 32, 1091-1102.

87. Vo, Q.T.; Oppelt, N.; Leinenkugel, P.; Kuenzer, C. Remote Sensing in mapping mangrove ecosystems-An object-based approach. Remote Sens. 2013, 5, 183-201.

88. Berberoglu, S.; Akin, A.; Atkinson, P.M.; Curran, P.J. Utilizing image texture to detect land-cover change in Mediterranean coastal wetlands. Int. J. Remote Sens. 2010, 31, 2793-2815.

89. Stein, B.R.; Zheng, B.J.; Kikkinidis, I.; Kayastha, N.; Seigler, T.; Goekkaya, K.; Gopalakrishnan, R.; Hwang, W.H. An efficient remote sensing solution to update the NCWI. Photogramm. Eng. Remote Sens. 2012, 78, 537-547.

90. ECognition, Trimble Inc. eCognition Reference Book; ECognition, Trimble Inc: Munich, Germany, 2012.

91. Holt, A.C.; Seto, E.Y.W.; Rivard, T.; Gong, P. Object-based detection and classification of vehicles from high-resolution aerial photography. Photogramm. Eng. Remote Sens. 2009, 75, 871-880.

92. De Chant, T.; Kelly, M. Individual object change detection for monitoring the impact of a forest pathogen on a hardwood forest. Photogramm. Eng. Remote Sens. 2009, 75, 1005-1013.

93. Clinton, N.; Holt, A.; Scarborough, J.; Yan, L.; Gong, P. Accuracy assessment measures for object-based image segmentation goodness. Photogramm. Eng. Remote Sens. 2010, 76, 289-299.

94. Baatz, M.; Schäpe, A. Multiresolution Segmentation-An optimization approach for high quality multi-scale image segmentation. In Angewandte Geographische Informationsverarbeitung XII; Wichmann: Heidelberg, Germany, 2000; pp. 12-23.

95. Dragut, L.; Tiede, D.; Levick, S.R. ESP: A tool to estimate scale parameter for multiresolution image segmentation of remotely sensed data. Int. J. Geogr. Inf. Sci. 2010, 24, 859-871.

96. Dragut, L.; Csillik, O.; Eisank, C.; Tiede, D. Automated parameterisation for multi-scale image segmentation on multiple layers. ISPRS J. Photogramm. Remote Sens. 2014, 88, 119-127.

97. Liu, D.; Xia, F. Assessing object-based classification: Advantages and limitations. Remote Sens. Lett. 2010, 1, 187-194.

98. Beller, E.; Salomon, M.; Grossinger, R. An Assessment of the South Bay Historical Tidal-Terrestrial Transition Zone; San Francisco Estuary Institute: Richmond, CA, USA, 2013.

99. Townsend, P.A.; Walsh, S.J. Remote sensing of forested wetlands: application of multitemporal and multispectral satellite imagery to determine plant community composition and structure in southeastern USA. Plant Ecol. 2001, 157, 129-149A.

100. Wright, C.; Gallant, A. Improved wetland remote sensing in Yellowstone National Park using classification trees to combine TM imagery and ancillary environmental data. Remote Sens. Environ. 2007, 107, 582-605.

101. Lenssen, J.; Menting, F.; van der Putten, W.H.; Blom, K. Control of plant species richness and zonation of functional groups along a freshwater flooding gradient. Oikos 1999, 86, 523-534.

102. Wang, L.; Dronova, I.; Gong, P.; Yang, W.; Li, Y.; Liu, Q. A new time series vegetation-water index of phenological-hydrological trait across species and functional types for Poyang Lake wetland ecosystem. Remote Sens. Environ. 2012, 125, 49-63. 
103. Li, G.; Lu, D.; Moran, E.; Dutra, L.; Batistella, M. A comparative analysis of ALOS PALSAR L-band and RADARSAT-2 C-band data for land-cover classification in a tropical moist region. ISPRS J. Photogramm. Remote Sens. 2012, 70, 26-38.

104. Silva, T.S.F.; Costa, M.P.F.; Novo, E.M.L.M.; Melack, J.M. A multisensor, multitemporal approach for monitoring herbaceous vegetation growth in the Amazon floodplain. In Proceedings of the 7th International Workshop on the Analysis of Multi-temporal Remote Sensing Images, Banff, UK, 25-27 June 2013.

105. Haralick, R.; Shanmuga, K; Dinstein, I. Textural features for image classification. IEEE Trans. Syst. Man Cybern. 1973, SMC3, 610-621.

106. Schoepfer, E.; Lang, S.; Albrecht, F. Object-fate analysis—Spatial relationships for the assessment of object transition and correspondence. In Object-Based Image Analysis-Spatial Concepts for Knowledge-Driven Remote Sensing Applications; Springer, Berlin, Germany, 2008; pp. 785-802.

107. McCleary, A.L.; Crews-Meyer, K.A.; Young, K.R. Refining forest classifications in the western Amazon using an intra-annual multitemporal approach. Int. J. Remote Sens. 2008, 29, 991-1006.

108. Stumpf, A.; Kerle, N. Object-oriented mapping of landslides using Random Forests. Remote Sens. Environ. 2011, 115, 2564-2577.

109. Gao, Y.; Francois Mas, J.; Kerle, N.; Navarrete Pacheco, J.A. Optimal region growing segmentation and its effect on classification accuracy. Int. J. Remote Sens. 2011, 32, 3747-3763.

110. Martha, T.R.; Kerle, N.; van Westen, C.J.; Jetten, V.; Kumar, K.V. Segment optimization and data-driven thresholding for knowledge-based landslide detection by object-based image analysis. IEEE Trans. Geosci. Remote Sens. 2011, 49, 4928-4943.

111. Witten, I.; Frank, E. Data Mining: Practical Machine Learning Tools and Techniques; Morgan Kaufmann: San Francisco, CA, USA, 2005.

112. Hall, M.; Frank, E.; Holmes, G.; Pfaringer, B.; Reutemann, P.; Witten, I. The WEKA Data Mining Software: An Update. Available online: http://www.cms.waikato.ac.nz/ ml/publications/ 2009/weka_update.pdf (accessed on 12 March 2015).

113. Ustin, S.L.; Gamon, J.A. Remote sensing of plant functional types. New Phytol. 2010, 186, 795-816.

114. Blaschke, T.; Tomljenovic, I. LidarScapes and OBIA. In Proceedings of the ASPRS 2012 Annual Conference, Sacramento, CA, USA, 19-23 March 2012.

115. GastelluEtchegorry, J.P.; Demarez, V.; Pinel, V.; Zagolski, F. Modeling radiative transfer in heterogeneous 3-D vegetation canopies. Remote Sens. Environ. 1996, 58, 131-156.

116. Hosoi, F.; Omasa, K. Voxel-based 3-D modeling of individual trees for estimating leaf area density using high-resolution portable scanning LiDAR. IEEE Trans. Geosci. Remote Sens. 2006, 44, 3610-3618.

117. Beland, M.; Baldocchi, D.D.; Widlowski, J.-L.; Fournier, R.A.; Verstraete, M.M. On seeing the wood from the leaves and the role of voxel size in determining leaf area distribution of forests with terrestrial LiDAR. Agric. For. Meteorol. 2014, 184, 82-97.

118. Addink, E.A.; de Jong, S.M.; Pebesma, E.J. The importance of scale in object-based mapping of vegetation parameters with hyperspectral imagery. Photogramm. Eng. Remote Sens. 2007, 73, 905-912. 
119. Chen, G.; Hay, G.J.; Castilla, G.; St-Onge, B.; Powers, R. A multiscale geographic object-based image analysis to estimate LiDAR-measured forest canopy height using Quickbird imagery. Int. J. Geogr. Inf. Sci. 2011, 25, 877-893.

120. Rowe, J. The ecosystem approach to forestland management. For. Chron. 1992, 68, $222-224$.

121. Lapin, M.; Barnes, B. Using the landscape ecosystem approach to assess species and ecosystem diversity. Conserv. Biol. 1995, 9, 1148-1158.

122. Barnes, B.V.; Zak, D.R.; Denton, S.R.; Spurr, S.H. Forest Ecology; John Wiley \& Sons, Inc: New York, NY, USA, 1998.

123. Zogg, G.P.; Barnes, B.V. Ecological classification and analysis of wetland ecosystems, Northern Lower Michigan, USA. Can. J. For. Res. 1995, 25, 1865-1875.

124. Albert, D.A. Regional Landscape Ecosystems of Michigan, Minnesota, and Wisconsin: A Working Map and Classification; General Technical Report NC-178; U.S. Dept. of Agriculture, Forest Service, North Central Forest Experiment Station: St. Paul, MN, USA, 1994.

125. Yu, Q.; Gong, P.; Clinton, N.; Biging, G.; Kelly, M.; Schirokauer, D. Object-based detailed vegetation classification with airborne high spatial resolution remote sensing imagery. Photogramm. Eng. Remote Sens. 2006, 72, 799-811.

126. Anders, N.S.; Seijmonsbergen, A.C.; Bouten, W. Segmentation optimization and stratified object-based analysis for semi-automated geomorphological mapping. Remote Sens. Environ. 2011, 115, 2976-2985.

127. Dragut, L.; Eisank, C.; Strasser, T. Local variance for multi-scale analysis in geomorphometry. Geomorphology 2011, 130, 162-172.

(C) 2015 by the author; licensee MDPI, Basel, Switzerland. This article is an open access article distributed under the terms and conditions of the Creative Commons Attribution license (http://creativecommons.org/licenses/by/4.0/). 